\title{
Current State of the Art on the Antioxidant Activity of Sage (Salvia spp.) and Its Bioactive Components
}

Authors

Efthymios Poulios, Constantinos Giaginis, Georgios K. Vasios

\section{Affiliation}

Department of Food Science and Nutrition, School of the Environment, University of the Aegean, Lemnos, Greece

\section{Key words}

Salvia officinalis, Lamiaceae, antioxidant activity, phenolic compounds, in vitro studies, in vivo animal studies, DPPH assay, ABTS assay

received September 11, 2019

revised December 19, 2019

accepted December 25, 2019

\section{Bibliography \\ DOI https://doi.org/10.1055/a-1087-8276}

published online January 23, 2020 | Planta Med 2020; 86: 224-238 @ Georg Thieme Verlag KG Stuttgart · New York | ISSN 0032-0943

\section{Correspondence}

Efthymios Poulios

Department of Food Science and Nutrition, School of the Environment, University of the Aegean

Metropolite Ioakeim 2, Myrina, Lemnos 81400, Greece

Phone: + 302254083120 , Fax: + 302254083109

epoulios@aegean.gr

Correspondence

Georgios K. Vasios

Department of Food Science and Nutrition, School of the

Environment, University of the Aegean

Metropolite Ioakeim 2, Myrina, Lemnos 81400, Greece

Phone: + 302254083116 , Fax: + 302254083109

vasios@aegean.gr

\section{ABSTRACT}

Common sage (Salvia spp., with the most common species Salvia officinalis) is an important medicinal and aromatic plant due to its bioactive components, secondary products of its metabolism. These components are mainly phenolics, terpenoids, polyphenols, and flavonoids. Many studies have identified their important role in fighting oxidative stress in cells and organisms, together with their anticancer, antimicrobial, and anti-inflammatory role. There are many methods measuring the antioxidant activity of sage phenolic components, usually based on radical scavenging of free radical species, such as 2,2-diphenyl-1-picrylydrazyl and 2,2'-azino-bis(3-ethylbenzothiazoline-6-sulfonic acid), and determining the absorbance of the reduced product by a photometric assay. In addition, there are several in vitro and in vivo studies determining the protection of sage extracts in cells in culture or animals, respectively, after induction of oxidative stress. In this review, results from the currently available studies that unravel the significant role of sage bioactive compounds, as antioxidant compounds, and the variety of methods used have been critically analyzed and discussed.

\section{Introduction}

Sage is an herbaceous, perennial plant of the family Lamiaceae, cultivated in South Europe, and characterized as a common, aromatic, medicinal, and food additive plant. The plant belongs to the genus Salvia containing more than 900 species, with the most representative Salvia officinalis L. The knowledge and use of several Salvia species (S. officinalis, Salvia fruticosa, and Salvia pomifera) can be dated back to the Greek Era and have a long history of culinary and effective medicinal use [1]. S. officinalis, known as common or Dalmatian sage, is a perennial, evergreen sub-shrub with woody stems, grayish leaves, and blue to purplish flowers with the calyx and corolla divided into two lips. It is native to the Middle East and East Mediterranean areas, but today it has been found and cultured throughout the world. S. officinalis is commonly used as a diary condiment in food, hydroalcoholic tincture, and tea used in traditional and folk medicine, from ancient years, for the treatment of several disorders. Many studies have revealed a wide range of beneficial biological activities for S. officinalis, including anticancer, anti-inflammatory, antinociceptive, antioxi- 
dant, antimicrobial, antimutagenic, anti-dementia, hypoglycemic, and hypolipidemic effects. Different chemical components have been found to be responsible for these activities [1-3].

Aerobic organisms generate small amounts of oxygen reduction intermediates during their metabolism, termed reactive oxygen species (ROS). ROS are a family of molecules that include superoxide anion $\left(\mathrm{O}_{2}^{-}\right)$, hydrogen peroxide $\left(\mathrm{H}_{2} \mathrm{O}_{2}\right)$, and hydroxyl radical ( $\mathrm{HO} \cdot)$, formed by the partial reduction of oxygen [4]. Conditions of increased production or decreased removal of these species may lead to enhanced steady state levels in cells, a situation generally called "oxidative stress" [5]. Oxidative stress results in the direct or indirect ROS-mediated damage of essential macromolecules such as nucleic acids, proteins, and lipids, and has been implicated in a variety of pathological conditions, including cancer, neurodegenerative diseases, cardiovascular diseases, and aging [6].

Plants produce secondary metabolites, categorized into four groups: terpenoids, phenolic compounds (such as flavonoids), alkaloids, and sulphur-containing compounds [7]. These molecules exert multiple antioxidant and anticancer properties. Half of the phenolic compounds found in plants are flavonoids, exerting a significant protective role against many diseases [8].

Sage species have been widely used for their antioxidant properties based on their phenolic compounds, and many different methods for the extraction and identification of these components have been reported [3]. The main polyphenolic compounds identified were rosmarinic acid, carnosic acid, salvianolic acid and its derivates (carnosol, rosmanol, epirosmanol, rosmadial, and methyl carnosate), tannins (salviatannin), essential oils (EOs) (including $\alpha$-thujone, b-thujone, 1,8 cineole, and camphor), flavones, phenolic acids, phenylpropanoid glycosides, triterpenoids, and diterpenes, $\gamma$-tocopherol, $\alpha$-tocopherol, carotenoids, gallic acid, 3-O-caffeoylquinic acid, 5-O-caffeoylquinic acid, caffeic acid, hesperetin, hispidulin, and genkwanin [9-11]. In Fig. 1, the most important bioactive compounds extracted from sage are depicted.

In this review, we summarize data from the currently available studies unraveling the significant antioxidant role of different sage extracts, due to their polyphenolic compounds, by in vitro and in vivo experiments.

\section{Methodology}

A systematic and comprehensive research of the current international literature was carried out by the use of a set of critical and representative key words, such as sage, Salvia officinalis, Lamiaceae, antioxidant activity, bioactive compounds, phenolics, in vitro studies, in vivo animal studies, DPPH assay, ABTS assay, etc. The most accurate scientific databases, e.g., Medline, Scopus, and Web of Science, were accessed during the period between May and July 2019, and yielded 85 studies that were used in the present review study.

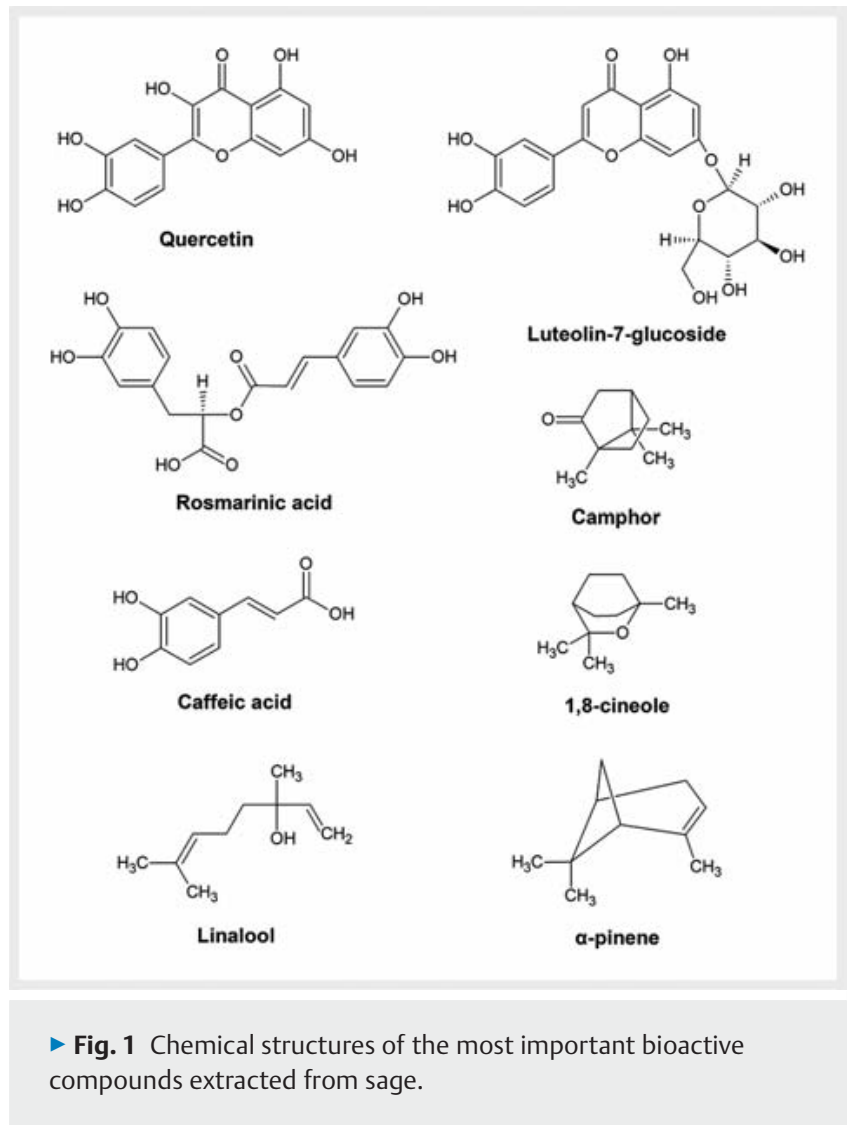

\section{Antioxidant Activity of Sage: In Vitro Studies}

\section{Sage extracts}

Many studies have currently been performed in order to evaluate the antioxidant activity of sage. Sage secondary metabolites, especially phenolic acids, flavonoids, and terpenes have been considered as responsible for its antioxidant activity, whereas a series of methods has been developed in order to measure this activity. Usually, methods for measuring the antioxidant potential of a plant extract are photometric methods, which determine the reduction of a free radical, such as 2,2-diphenyl-1-picrylydrazyl (DPPH) [12] or 2,2'-azino-bis(3-ethylbenzothiazoline-6-sulfonic acid) (ABTS) [13].

In a recent study, Rowshan and Najafian investigated the contents and antioxidant activities of the aerial parts of Salvia multicaulis from the Iran flora. Polyphenols with the highest amounts included rosmarinic acid, catechin, vanillin, chlorogenic acid, quercetin, and p-coumaric acid, whereas the plant showed high DPPH scavenging activity [14].

Pereira and co-workers performed a comparative study of three Salvia species: Salvia elegans Vahl., Salvia greggii A. Gray, and S. officinalis L. Their decoctions were investigated for their health benefit properties, in particular with respect to antioxidant activity and inhibitory ability towards key enzymes that in diabetes and obesity ( $\alpha$-glucosidase, $\alpha$-amylase, and pancreatic lipase). Additionally, the phenolic profiles of the three decoctions were determined and correlated with the beneficial properties. The 
S. elegans decoction was the most promising in regard to the antioxidant effects, namely, in the scavenging capacity of the free radicals $\mathrm{DPPH} \bullet, \mathrm{NO} \bullet$, and $\mathrm{O} \bullet^{-}$, and the ability to reduce $\mathrm{Fe}^{3+}$, as well as the most effective inhibitor of $\alpha$-glucosidase $\left(\mathrm{EC}_{50}=36.0 \pm\right.$ $2.7 \mu \mathrm{g} / \mathrm{mL}$ vs. $\mathrm{EC}_{50}=345.3 \pm 6.4 \mu \mathrm{g} / \mathrm{mL}$ and $71.2 \pm 5.0 \mu \mathrm{g} / \mathrm{mL}$ for S. greggii and $S$. officinalis, respectively). This superior activity of the $S$. elegans decoction over those of S. greggii and S. officinalis was, overall, highly correlated with its richness in caffeic acid and derivatives. In turn, the $S$. officinalis decoction exhibited considerable inhibitory capacity against xanthine oxidase activity. This fact could be ascribed to its high content of flavones, in particular, the glycosidic forms of apigenin, scutellarein, and luteolin [15].

Almada-Taylor and co-workers investigated the antioxidant and enzyme inhibitory properties of five extracts from the aerial parts of another Salvia species, Salvia pachyphylla Epling ex Munz. These properties were analyzed by performing a set of standard assays, such as DPPH and $\beta$-carotene-linoleic acid assay. The extract obtained with dichloromethane showed the most variety of components, as they yielded promising results in all completed assays. Furthermore, the extract obtained with ethyl acetate exhibited the greatest antioxidant activity, as well as the best xanthine oxidase inhibitory activity [16]. In a similar study, Kamatou and co-workers investigated the antioxidant activity of three closely related South African Salvia species (Salvia stenophylla, Salvia repens, and Salvia runcinata), by using the DPPH assay. The solvent extracts exhibited antioxidant properties, whereas EOs displayed poor antioxidant activity. Overall, S. runcinata displayed the most favorable activity of all three taxa tested with an $\mathrm{IC}_{50}$ of $6.09 \mu \mathrm{g} / \mathrm{mL}$ (antioxidant activity) [17].

Pavić and co-workers extracted carmosol and carnosic acid from $S$. officinalis by using supercritical $\mathrm{CO}_{2}$ extraction, after changing some parameters. The antioxidant activities of sage extracts were evaluated by the DPPH assay. Sage extract obtained at $30 \mathrm{MPa}$ and $40^{\circ} \mathrm{C}$ with a $2 \mathrm{~kg} \cdot \mathrm{h}^{-1} \mathrm{CO}_{2}$ flow rate with a carnosic acid content of $72 \mu \mathrm{g} / \mathrm{mg}$ and carnosol content of $55 \mu \mathrm{g} / \mathrm{mg}$ exhibited the highest antioxidant activity $(80.0 \pm 0.68 \%)$ amongst the investigated supercritical fluid extracts at a $25 \mu \mathrm{g} / \mathrm{mL}$ concentration [18].

Safari and co-workers evaluated the antiglycation and antioxidant activity of four Iranian medical plant extracts, including Salvia hydrangea. Phenolic, flavonoids content, and antioxidant activity were evaluated. The multistage glycation markers fructosamines (early stage), protein carbonyls (intermediate stage), and $\beta$-aggregation of albumin were investigated in the bovine serum albumin (BSA) glucose system. All plants showed high potency of scavenging the free radical DPPH and glycation inhibition. There was a significant correlation between antioxidant and anti-glycation activity. Also, the antioxidant and anti-glycation capacity of extracts correlated with total phenolic and flavonoid content [19]. In another study, total polyphenolic profile, antioxidant properties, and an antiplatelet effect of short-toothed sage (Salvia brachyodon Vandas) were analyzed and compared to S. officinalis. The content of total flavonoids was $0.08-0.23 \%$ and of phenolic acids $0.47-3.04 \%$. The antioxidant DPPH assay showed a higher antioxidant capacity of S. brachyodon [29-36 mg/mL of gallic acid equivalents (GAE)] than that of $S$. officinalis. In a functional test of primary hemostasis, extracts of $S$. brachyodon inhibited platelet aggregation in a nanomolar concentration (21 nM), thus showing potential in the prevention of thrombus formation as a functional food or dietary supplement. Antiplatelet activity was significantly related to antioxidant capacity, indicating that prevention of aggregation may be not ascribed to an individual component, but it could be rather a result of a synergistic effect of polyphenols [20].

In addition, the antioxidant level of commercial tinctures from three Lamiaceae plants, including S. officinalis, were determined by the Folin-Ciocalteu (FC) method, DPPH radical scavenging technique, and ABTS assay. Total phenolic content ranged from 0.24 to $3.99 \mathrm{mg} / \mathrm{mL}$ GAE. Antioxidant activity in the ABTS assay, calculated as Trolox equivalent antioxidant capacity (TEAC), ranged from 23.5 to $35.6 \mu \mathrm{mol}$ Trolox $/ \mathrm{mL}$, while in the DPPH method, the $\mathrm{EC}_{50}$ value ranged from 0.04 to $0.07 \mathrm{~mL} /$ assay. Notably, radical scavenging activity was correlated with total phenolic content. Correlations between ABTS and FC methods, DPPH and FC methods, and ABTS and DPPH methods were calculated [21]. Additionally, the antioxidant activity and the phenolic compounds of extracts of Salvia fruticosa Mill. were studied by Boukhary and co-workers. In fact, total phenolic contents were estimated using FC reagent, and HPLC experimentation was performed to identify phenolic constituents, while antioxidant activity was determined using the DPPH radical scavenging assay. Different plant extracts demonstrated strong radical scavenging activity, whereas the eth$\mathrm{yl}$ acetate extract had the highest value in the roots and the lowest in the aerial parts. This antioxidant activity was correlated with the total phenolic content of different extracts, where rutin and luteolin were the most abundant constituents [22].

Garcia and co-workers evaluated the in vitro ability of aqueous and hydroalcoholic extracts of Brazilian S. officinalis to scavenge the free radicals DPPH and ABTS, and measured their catalase (CAT-like) and superoxide dismutase (SOD-like) activities. In vitro antioxidant analysis for both extracts indicated promising activities [23].

The antioxidant activity of six different Lamiaceae plant extracts, including ethanolic extracts of $S$. officinalis, were also screened for antioxidant activities by DPPH radical scavenging, HAPX (hemoglobin ascorbate per oxidase activity inhibition), and EPR (electron paramagnetic resonance) methods, showing promising results of antioxidant activity [24]. Furthermore, six medicinal plants, including S. officinalis, were used to compare their extracts obtained by Soxhlet (hexane) extraction, maceration with ethanol (EtOH), and $\mathrm{SC}-\mathrm{CO}_{2}$ extraction (targeted on coumarin content by HPLC with ultraviolet detection, HPLC-UV), DPPH scavenging capacity, and total phenols (TPs) content (by the FC assay). In fact, EtOH extracts of all plants exhibited the highest DPPH scavenging capacity. SC- $\mathrm{CO}_{2}$ extracts exhibited antiradical capacity similar to the hexane extracts, while $\mathrm{S}$. officinalis $\mathrm{SC}-\mathrm{CO}_{2}$ extracts were the most potent (95.7\%). Interestingly, total phenolic content was strongly associated with DPPH scavenging capacity of the extracts [25].

In a similar study, the antioxidant activities from some common Mediterranean plant species, including sage, collected from different places in Jordan were evaluated according to the DPPH method. S. officinalis extract showed the highest antioxidant activity (91\%) among them. A strong correlation between antioxidant activity and total phenolic content was found [26]. Addition- 
ally, Neagu and co-workers obtained 8, 10, and 15\% (mass concentration) hydroalcoholic extracts in $50 \%$ ethanol from S. officinalis. The antioxidant capacity was assessed by DPPH and ABTS assays. A proportionality between polyphenol and flavone concentrations and antioxidant capacity was observed, with the highest antioxidant activity being found in the case of extracts in $50 \%$ ethanol with $10 \%$ plant mass. The obtained results supported evidence that the applied membranous (ultrafiltration) procedures resulted in some concentrated $S$. officinalis extracts having a high antioxidant capacity (89.89\% of DPPH inhibition) [27].

In another study, rosmarinic acid was separated and identified on the basis of HPLC-UV-mass spectrometry data in $80 \%$ methanol and in water extracts from the leaves of Salvia species (S. officinalis, Salvia glutinosa, Salvia aethiopis, Salvia sclarea) as a dominant radical scavenger towards the DPPH stable radical in the HPLC-DPPH system. The content of rosmarinic acid in the plants was calibrated and quantitated from chromatograms obtained by UV detection at $280 \mathrm{~nm}$. It was found that the concentration ranged from 13.3 to $47.3 \mathrm{mg}$ of the phenolic acid $/ \mathrm{g}$ of dried leaves of all plants tested. S. glutinosa and S. sclarea had the highest concentration of rosmarinic acid. The HPLC-DPPH system was calibrated for quantitative DPPH scavenging assessment of rosmarinic acid. The results revealed a significant correlation between the rosmarinic acid concentration and antiradical activity [28].

Interestingly, TLC with post-chromatographic derivatization with the methanol solution of DPPH was used for measuring the radical scavenging activity of 19 Salvia species grown and cultivated in Poland. More to the point, chromatography was performed on the silica gel layers with the use of two eluents, one for the resolution of the less polar compounds, and the other one for the resolution of the medium and highly polar ones. The plates were sprayed with the vanillin-sulfuric acid reagent to produce chemical fingerprints, and with DPPH solution to generate free radical scavenging fingerprints. With four Salvia species, it was revealed that their strong free radical scavenging properties were not ascribed to the presence of polar flavonoids and phenolic acids, but to the presence of several free radical scavengers in the less polar fraction. Because of the similarities in both the chromatographic and the free radical scavenging fingerprints, Salvia triloba could be considered a possible equivalent of the pharmacopoeial species $S$. officinalis. Finally, fingerprints developed in the experiments proved useful for the analysis of complex extracts of the different Salvia species [29]. In a similar study, TLC coupled with DPPH staining was used to analyze phenolic acid fractions of selected Salvia species. In particular, documented video scans were processed by means of an image processing program. Free phenolic acid fractions as well as fractions containing phenolic acids derived from basic and acidic hydrolysis were analyzed and compared for selected sage species. The analyzed samples along with caffeic acid (standard) were chromatographed on silica gel plates, with toluene-ethyl acetate-formic acid $(60: 40: 1, \mathrm{v} / \mathrm{v} / \mathrm{v})$ as the mobile phase. The extracts were investigated with respect to the activity of caffeic acid. It was found that caffeic acid was more abundant in the fractions derived from basic hydrolysis. Moreover, this compound was not detected in any of the fractions obtained after acidic hydrolysis. Interestingly, S. officinalis and S. triloba exerted similar free radical scavenging activity fingerprints obtained from all the analyzed fractions [30].

Miura and co-workers isolated a new abietane diterpenoid analogue, 12-O-methyl carnosol, from the leaves of S. officinalis, together with 11 abietane diterpenoids, 3 apianane terpenoids, 1 anthraquinone, and 8 flavonoids. Antioxidant activity of these compounds along with four flavonoids isolated from thyme (Thymus vulgaris L.) was evaluated by the oil stability index method using a model substrate oil, including methyl linoleate in silicone oil at $90^{\circ} \mathrm{C}$. Notably, carnosol, rosmanol, epirosmanol, isorosmanol, galdosol, and carnosic acid exhibited remarkably strong activity, which was comparable to that of $\alpha$-tocopherol. The activity of miltirone, atuntzensin A, luteolin, 7-O-methyl luteolin, and eupafolin was comparable to that of butylated hydroxytoluene. Interestingly, the activity of these compounds was mainly ascribed to the presence of ortho-dihydroxy groups. The DPPH radical scavenging activity of these compounds showed similar results [31].

Additionally, crude polysaccharides, isolated from the aerial parts of $S$. officinalis by sequential extraction with water $(A)$, hot ammonium oxalate (B), dimethyl sulfoxide (C), $1 \mathrm{M}(\mathrm{D})$, and $4 \mathrm{M}$ (E) potassium hydroxide solutions, and six ion-exchange fractions of A were examined for their ability to inhibit liposome lipid peroxidation by hydroxyl radicals, and to reduce DPPH radical content. The highest inhibition of liposome lipid peroxidation was found with crude polysaccharides $A, B$, and D, and antioxidant activities reached approximately $37 \%$. The purified fractions A1 and A2 inhibited the liposome peroxidation to approximately $35 \%$. However, the radical scavenging abilities of the most active crude polysaccharides $A, B$, and $C$ on DPPH radicals were found in the range $80-90 \%$, while the most active purified fractions $A 3-A 6$ in three- or fourfold doses achieved $75-92 \%$. The least effective tested polysaccharides succeeded $20 \%$ inhibition using both methods [32].

In another study, Oregano vulgare L. ssp. hirtum (Greek oregano), S. fruticosa (Greek sage), and Satureja hortensis (summer savory) were examined as potential sources of phenolic antioxidant compounds. The antioxidant capacities (antiradical activity by the DPPH assay, phosphatidylcholine liposome oxidation, Rancimat test) and total phenolic content were determined in the ethanol and acetone extracts of the dried material obtained from the botanically characterized plants. The ground material was also tested by the Rancimat test for its effect on the stability of sunflower oil. The data indicated that ground material and both ethanol and acetone extracts had antioxidant activity. Chromatographic [TLC, reverse-phase (RP)-HPLC] and NMR procedures were employed to cross-validate the presence of antioxidants in ethanol and acetone extracts. The major component of all ethanol extracts was rosmarinic acid, as determined by both RP-HPLC and NMR. Moreover, chromatography indicated the presence of other phenolic antioxidants, mainly found in the acetone extracts. The presence of the flavones luteolin and apigenin and the flavonol quercetin was confirmed in the majority of the extracts by the use of a novel ${ }^{1} \mathrm{H}-\mathrm{NMR}$ procedure [33]. In a previous study, 6 O-caffeoyl- $\beta$-D-fructofuranosyl-( $2 \rightarrow 1)$ - $\alpha$-D-glucopyranoside and 1 -O-caffeoyl- $\beta$-D-apiofuranosyl- $(1 \rightarrow 6)$ - $\beta$-D-glucopyranoside of S. officinalis were found to be moderately active as antioxidants in the DPPH test and metmyoglobin test [34]. 
Another antioxidant assay mainly used is the feric reducing antioxidant power (FRAP) assay. In this aspect, Ramu and Dhanabal evaluated the antioxidant activity of ethanol extracts from the leaves of S. officinalis using nitric oxide scavenging, hydrogen peroxide scavenging, the FRAP assay, and lipid peroxidation methods. This study supported evidence that the higher amount of flavonoids and phenolic compounds may correspond to the greater antioxidant activity identified [35]. In addition, Gerenalic and coworkers determined the phenolic content and antioxidant capacity of S. officinalis leaves collected during different vegetation periods. More to the point, separation and quantification of the individual phenols were performed by RP-HPLC coupled with a photodiode array (PDA) detector using an internal standard, while the contents of total phenols, flavonoids, flavones, and flavonols were determined spectrophotometrically. The antioxidant properties of the sage leaf extracts were evaluated using five different antioxidant assays (FRAP, DPPH, ABTS, Briggs-Rauscher reaction, and $\beta$-carotene bleaching). Interestingly, all extracts were extremely rich in phenolic compounds, and provided high antioxidant properties. However, it should be noted that the phenophase in which the leaves were collected affected the phenolic composition of the sage extracts and, consequently, their biological activity, with the extract richest in total flavonoids and the best antioxidant properties being the May extract [36]. Furthermore, the total phenolic and flavonoid contents and DPPH and FRAP antioxidant capacities of 19 accessions of S. officinalis from the sage collection of the genebank in Gatersleben (Germany) were evaluated. The major phenolic compounds of sage, which are rosmarinic acid, caffeic acid, carnosol, and carnosic acid, were quantified by RP-HPLC. The aerial parts of different individual plants of each accession were collected in 2 consecutive years from the same experimental field at the beginning of their flowering period. The results demonstrated a high variability between accessions. A general decreasing tendency from 2007 to 2008 was observed in most of the estimated parameters, which were total phenolic, total flavonoids, rosmarinic acid, and caffeic acid contents and DPPH antioxidant activity. A slight opposite trend was obtained with the FRAP antioxidant capacity. In addition, low but variable quantities of carnosol and carnosic acid were evaluated in the sample extracts. Individual plants within accessions were identified with high phenolic content and strong antioxidant activity. The rosmarinic acid content showed up to an 8-fold difference between the lowest and the highest values. Overall, this study demonstrated a high variability in secondary metabolites present in sage, which could be used for breeding of highly antioxidative genotypes of S. officinalis [37].

Grzegorczyk-Karolak and Kiss evaluated the polyphenol profile and antioxidant activity of aqueous (decoction and infusion) and hydroethanolic extracts of the aerial parts of field-grown Salvia viridis. In fact, the antioxidant effect was evaluated by the FRAP, DPPH, ABTS, and thiobarbituric acid reactive substances (TBARS) methods. The presence of a high polyphenol level indicated high antioxidant activity for both the infusion and the hydroalcoholic extracts [38].

Notably, optimized pressurized liquid extraction (PLE) conditions to maximize the antioxidant activity (FRAP assay) and total polyphenol content (TP) of the extracts from three spices of the
Lamiaceae family (sage, basil, and thyme) were applied. In fact, optimal conditions with regard to extraction temperature (66$129^{\circ} \mathrm{C}$ ) and solvent concentration (32-88\% methanol) were identified using response surface methodology (RSM). For all three spices, it was showed that $129^{\circ} \mathrm{C}$ was the optimum temperature with regard to antioxidant activity. Optimal methanol concentrations with respect to the antioxidant activity of sage was $58 \%$. Antioxidant activity yields of the optimal PLE were significantly higher than solid/liquid extracts. Predicted models were also highly significant for both TP and FRAP values in all of the spices [39].

Another antioxidant method commonly used is oxygen radical absorbance capacity (ORAC). In this aspect, the antioxidant capacity in extracts of 27 culinary and 12 medicinal herbs, including sage, was determined by using this assay, while total phenolic content was determined by the FC method. The ORAC values and total phenolic content for the medicinal herbs ranged from 1.88 to $22.30 \mu \mathrm{mol}$ of Trolox equivalents (TE)/g of fresh weight (an equivalent of vitamin $\mathrm{E}$ ) and 0.23 to $2.85 \mathrm{mg}$ of $\mathrm{GAE} / \mathrm{g}$ of fresh weight, respectively. Moreover, the ORAC values and total phenolic content for the culinary herbs ranged from 2.35 to $92.18 \mu \mathrm{mol}$ of TE/g of fresh weight and 0.26 to $17.51 \mathrm{mg}$ of GAE/ $\mathrm{g}$ of fresh weight, respectively. These were also much higher than values found in the medicinal herbs. A linear relationship between ORAC values and total phenolic contents of the medicinal herbs and culinary herbs was recorded [40].

Walch and co-workers developed a methodology that utilizes ${ }^{1} \mathrm{H}-\mathrm{NMR}$ spectroscopy in order to simultaneously analyze toxic terpenes (thujone and camphor), major polyphenolic compounds, total antioxidant capacity (ORAC assay), and the FC index in foods and medicines containing sage. The quantitative determination of rosmarinic acid [limit of detection (LOD) $=10 \mathrm{mg} / \mathrm{L}$ ] and total thujone ( $\mathrm{LOD}=0.35 \mathrm{mg} / \mathrm{L}$ ) was obtained using direct integration of the signals. For other parameters (derivatives of rosmarinic acid, carnosol and flavone glycosides, ORAC, and FC index), chemometric regression models were obtained separately for alcoholbased tinctures and aqueous tea infusions. Moreover, the relative standard deviations for authentic samples were below $10 \%$. The developed methodology was applied for the analysis of a wide variety of sage products $(n=108)$. The total thujone content in aqueous tea infusions was found to be in the range of not detectable (nd) to $37.5 \mathrm{mg} / \mathrm{L}$ (average $9.2 \mathrm{mg} / \mathrm{L}$ ), while tinctures contained higher levels (range nd- $409 \mathrm{mg} / \mathrm{L}$, average $107 \mathrm{mg} / \mathrm{L}$ ). The camphor content varied from 2.1 to $43.7 \mathrm{mg} / \mathrm{L}$ in aqueous infusions and from non-detectable to $748 \mathrm{mg} / \mathrm{L}$ in tinctures (averages were 14.1 and $206 \mathrm{mg} / \mathrm{L}$, respectively). Phenolic compounds were also detected in the majority of the investigated products. Thus, ${ }^{1} \mathrm{H}-\mathrm{NMR}$ spectroscopy was proven to have the ability to holistically control all important adverse and beneficial compounds in sage products in a single experiment, considerably saving time, resources, and costs as NMR [41].

Celano and co-workers evaluated the potential of distillation wastewaters (DWWs) produced by the distillation of packaged and sage wastes, performing chemical and antioxidant characterization. DWWs demonstrated high levels of total phenolic compounds (TPCs; 152-443 mg GAE/100 mL) and strong antioxidant capacities in ORAC, DPP and ABTS assays (1101-4720, 635- 
4244, and 571-3145 $\mu \mathrm{mol} \mathrm{TE} / 100 \mathrm{~mL}$, respectively). Highly significant correlations of TEAC values with TPC and rosmarinic acid contents revealed that phenolic compounds and high RA content were responsible for DWWs antioxidant properties [42].

In another study, sage teas prepared from commercially available products were chemically analyzed for polyphenolic content using liquid chromatography, for antioxidant potential using the ORAC assay, and for the FC index. The sage teas showed a high variation for all parameters studied (up to 20-fold differences for rosmarinic acid). Both univariate and multivariate analyses showed that the antioxidant potential, which varied between 0.4 and $1.8 \mathrm{mmol} \mathrm{TE} / 100 \mathrm{~mL}$, was highly dependent on rosmarinic acid and its derivatives. The FC index also showed a high correlation to these polyphenols and could therefore be used as a screening parameter for sage tea quality. The considerable differences in polyphenolic composition and antioxidant capacity between the brands led to a demand for quality standardization, especially if these sage teas are to be used for therapeutic purposes [43].

Zupkó and co-workers evaluated the protective effects of 11 Salvia species native to Europe against enzyme-dependent and enzyme-independent lipid peroxidation. Interestingly, the $50 \%$ aqueous methanolic extracts of the leaves of all tested plants were found to be more effective than the positive control $\alpha$-tocopherol acid succinate. The extracts of Salvia candelabrum, Salvia ringens, Salvia tomentosa, Salvia nemorosa, and S. glutinosa displayed considerable concentration-dependent antioxidant effects, which were comparable to those of S. officinalis. The concentrations of flavonoids, hydroxycinnamic acids, and TPCs in each extract were quantified with the aim of clarifying the connection between activity and chemical composition [44]. This method was also used by Hohmann and co-workers in order to determine the antioxidant activity of aqueous methanolic extracts from three medicinal Lamiaceae species, including sage. Notably, all these extracts caused a considerable concentration-dependent inhibition of lipid peroxidation. Phenolic components present in the plant extracts were evaluated for antioxidant activity and were found effective in both tests. Their concentrations in each extract were determined by TLC densitometry [45].

The antioxidant properties of the wild growing sage species, Salvia reflexa Hornem., were investigated by Malencić and coworkers. The presence of superoxide $\left(\mathrm{O}_{2}^{-}\right)$and hydroxyl $\left(\mathrm{OH}^{-}\right)$ radicals, malonyldialdehyde (MDA), reduced glutathione (GSH), and total flavonoids were observed in the above-ground parts of plant, as well as activities of the antioxidant enzymes SOD and peroxidase (P-ase). The potential antioxidant activity of the methanol: water extract was assessed based on scavenging activity of stable DPPH free radicals. By means of TLC and LC/MS, a screening for secondary plant products was also performed. Significant quantities of $\mathrm{O}_{2}^{-}$and $\mathrm{OH}^{-}$radicals and MDA were observed. Thus, this species exhibited high SOD and P-ase activities, as well as a content of total flavonoids. The dominant naturally occurring compound was rosmarinic acid [46].

In another study, the antioxidant activity of extracts obtained from different parts of Georgian flora species, including S. officinalis, was determined. Comparison with ethylene-tetraacetate and $\alpha$-tocopherol revealed high efficacy for all extracts. Moreover, 45 individual phenolic compounds were isolated and described by chemical examination of biologically active objects. S. officinalis extract turned out to be the most active. Interestingly, the chemical study revealed the dominant content of condensed tannins and low molecular weight phenolic compounds, which may be attributed to the high antioxidant activity. The biologically active anti-atherosclerotic food additive "Salbin" was developed on the basis of S. officinalis phenolic compounds [47]. In a similar study, the total content of phenolic compounds (TPC) and antioxidant capacity indicators were evaluated for the extracts of 10 Salvia species consecutively isolated by supercritical carbon dioxide $\left(\mathrm{SFE}-\mathrm{CO}_{2}\right)$ and pressurized liquid extraction with ethanol and water. In fact, antioxidant properties of solid plant material were evaluated by the direct antioxidant capacity measurement by the so-called QUENCHER method. Moreover, total antioxidant capacity values were calculated by integrating the results obtained for all extracts and the whole plant material. It was shown that TPC and antioxidant capacity of the extracts were greatly dependent on the plant species and extraction solvent. Ethanol extracts possessed significantly higher antioxidant capacity and TPC compared to the extracts isolated with other solvents. In general, all studied Salvia species demonstrated strong antioxidant capacity; however, the antioxidant potential of such species as Salvia forsskaolii and Salvia verticillata was the highest and comparable with that of S. officinalis [48].

Antioxidant activity, total phenolics content, and a profile of the main hydroxycinnamic acids (HCAs), including caffeic, ferulic, coumaric, and rosmarinic acids, was determined in ethanolic extracts from medicinal plant species cultivated in western Romania, including $S$. officinalis. The results indicated that TPC was 73.76-274.73 mg GAE/g and the antioxidant activity was 2.32$2.87 \mathrm{mM} \mathrm{Fe} / 2 / 100 \mathrm{~g}$. A strong positive correlation between TPC and the antioxidant activity in the investigated samples was found. Regarding the HCA profile obtained by HPLC, the results demonstrated that rosmarinic acid represented the main identified compound [49]. In a similar study, antioxidant activity of aqueous (prepared by infusion and decoction) and methanol/ water $(80: 20, v / v)$ extracts of $S$. officinalis were evaluated and characterized in terms of phenolic compounds. Notably, the decoction and methanol/water extract showed the most pronounced antioxidant activity, being positively related with their phenolic composition. The highest concentration of phenolic compounds was observed in the decoction, followed by the methanol/water extract and infusion [50]. More to the point, four organic solvent extracts from aqueous infusions of sage were examined. HPLC analyses of these extracts led to the separation of a number of components, of which four were identified and quantified by the use of standard compounds of known chromatographic HPLC profiles. These compounds were the diterpenes carnosic acid, carnosol, and rosmanol, and the hydroxycinnamic acid caffeic acid. The antioxidant activity and polyphenol content were determined in the four organic solvent extracts and the leftover aqueous fraction. Both polyphenolic and non-polyphenolic substances present in the extracts arose as significant contributors to the observed antioxidant activity of the derived extracts, and thus sage itself. In this sense, they reflected the antioxidant potential of the aqueous infusions of sage toward ROS generated 
through variable mechanisms of iron-promoted oxidative processes [51].

Finally, in a different study, Mariutti and co-workers investigated the effects of the addition of sage and garlic in chicken meat on lipid and cholesterol oxidation, having as prooxidant factors the addition of salt, thermal treatment, and frozen storage. The content of unsaturated fatty acids did not change in the presence of sage. On the contrary, with garlic, the content of these fatty acids decreased after cooking and storage. Hexanal and pentanal contents were lower in patties containing sage, and higher in those with garlic. The 7-ketocholesterol was the cholesterol oxide found in a higher amount in raw chicken on day 0 , while the formation of $7 \beta$ - and $7 \alpha$-hydroxycholesterol was verified only from day 30 on. Cooking and storage resulted in an increase of total cholesterol oxides and a decrease of $\alpha$ - and $\gamma$-tocopherol. In view of the above considerations, sage was considered effective in controlling lipid and cholesterol oxidation, minimizing the prooxidant effects of salt, cooking, and storage. However, garlic presented no effect as an antioxidant and accelerated lipid oxidation [52].

\section{Sage essential oils}

EOs from sage extracts, which contain various bioactive molecules, have extensively been studied for their antioxidant activity. More to the point, four EOs from S. officinalis cultivated in Spain (Murcia Province) were analyzed for their antioxidant activity against free radicals and as ferric reducing and ferrous chelating agents. All samples exerted moderate biological activity due to the compounds they contained, such as linalool or terpinene. Some of their components inhibited both lipoxygenase and acetylcholinesterase enzymes, which are related to inflammatory illnesses and Alzheimer's disease, respectively [53]. In a more recent study, the EOs of some officinal plants from Abruzzo territory (Italy), including S. officinalis, were evaluated for their antioxidant activities. The TPC and the antioxidant capacity were assessed by means of the FC method, and TEAC/ABTS, FRAP, and DPPH assays. S. officinalis EO showed $\alpha$-thujone (41\%) as the main constituent $(p<0.05)$, followed by camphor $(12 \%)$ and equal ratios $(p>0.05)$ of 1,8-cineole/isocaryophyllene/humulene/ledene (total abundance of $42 \%$ ). Its extract showed $0.178 \pm 0.008 \mathrm{mg} \mathrm{GAE} / \mathrm{g}$ EOs for TPC, $12.304 \pm 0.022 \mathrm{mg} \mathrm{TE} / \mathrm{g}$ EOs for the FRAP assay, $8.709 \pm$ $0.885 \mu \mathrm{g} \mathrm{TE} / \mathrm{g}$ EOs for the DPPH assay, and $0.098 \pm 0.005 \mathrm{mmol}$ $\mathrm{TE} / \mathrm{g}$ EOs for the ABTS assay [54]. In a similar study, the EOs from S. officinalis from Tunisia were analyzed for antioxidant activity by complementary tests. This study showed DPPH radical scavenging $\left(I C_{50}=6.7 \mathrm{mg} / \mathrm{mL}\right)$, linoleic acid peroxidation $\left(I C_{50}=9.6 \mathrm{mg} /\right.$ $\mathrm{mL})$, and ferric reducing assays $\left(\mathrm{IC}_{50}=28.4 \mathrm{mg} / \mathrm{mL}\right)$ [55]. In another study, the variation in the chemical composition of the EOs of S. officinalis, growing in different habitats, was studied. Analysis of some representative polyphenolic compounds and antioxidant activity was performed using post-distilled dry samples. Rosmarinic acid, carnosol, and carnosic acid were the prevalent compounds of S. officinalis methanolic extracts. This study revealed differences in the polyphenolic composition and also exhibited antioxidant and radical scavenging activities at different levels. However, within the used methods, only the DPPH assay showed significant differences in free radical scavenging activity among samples collected in different regions. Plants collected in the coastal regions Soliman and Kelibia accumulated more polyphenolic compounds, which are known to be responsible for the main antioxidant activity of sage (rosmarinic acid, carnosol, and carnosic acid) than those growing inland at Bou Arada and Sers. Moreover, the former presented higher radical scavenging activity [56].

Dawidowicz and Olszowy discussed the similarities and differences between the antioxidant activities of some EOs from thyme (T. vulgaris), basil (Ocimum basilicum), peppermint (Mentha piperita), clove (Caryophyllus aromaticus), summer savory (S. hortensis), sage (Salvia hispanica), and lemon (Citrus limon L. Burm.) and of their main components (thymol or estragole or menthol or eugenol or carvacrol or camphor or limonene) estimated by using $\mathrm{DPPH}, \mathrm{ABTS}$, and $\beta$-carotene bleaching assays. The obtained data showed that the antioxidant properties of the EOs did not always depend on the antioxidant activity of its main component, and that they could be modulated by their other components. The main conclusions of the above study concerning the interaction of EO components depend on the type of method applied for assessing the antioxidant activity. When comparing the antioxidant properties of EOs and their main components, the concepts of synergism, antagonism, and additivity were very relevant [57].

In another study, S. officinalis EOs were isolated from the plant's commercial dried aerial parts by hydrodistillation with different distillation times. The antioxidant ability was measured using DPPH, TBARS, and deoxyribose assays for the scavenging of hydroxyl radical, an assay for site-specific actions, and a 5-lipoxygenase assay. The time of hydrodistillation influenced the antioxidant activity. With the DPPH method, the EOs isolated for 2 and $3 \mathrm{~h}$ were stronger free radical scavengers, while with the TBARS method, the highest antioxidant values were obtained in the EOs isolated for 30 min and 2 and $3 \mathrm{~h}$. Hydroxyl radical scavenging and lipoxygenase activity assays showed the best results with EOs isolated for 1 and $3 \mathrm{~h}$. With the deoxyribose method, sage oils at concentrations $<1000 \mathrm{mg} / \mathrm{L}$ showed better activity than mannitol [58].

Moreover, the EOs and the phenolic composition along with the antioxidant activity of Rosmarinus officinalis L. and S. fruticosa Miller collected on Zakynthos Island (Ionian Sea, Greece) were investigated. The EOs' composition of the plants was characterized by the presence of 1,8-cineole. Mean values of the antioxidant activities of rosemary and sage EOs indicated slight differences. The antioxidant activity of sage oil was correlated with the oxygenated sesquiterpenes and diterpenes concentrations. Concerning the methanolic extracts, a close relationship between the phenolic content and the development stage during the vegetative cycle of these plants was observed. The identified flavonoids, except rutin, seemed to increase with the advancement of developmental stages, while phenolic acids followed the opposite pattern. The antioxidant activity was correlated with the amount of TPC [59]. In a similar study, the EOs of $R$. officinalis $L$. and S. officinalis $L$. were analyzed by means of GC-MS and assayed for their antioxidant activity as a free radical scavenging capacity (RSC) together with the effect on lipid peroxidation (LP). RSC was assessed by measuring the scavenging activity of EOs on DPPH and hydroxyl radicals. Effects on LP were evaluated following the activities of EOs in $\mathrm{Fe}^{+2}$ / 
ascorbate and $\mathrm{Fe}^{+2} / \mathrm{H}_{2} \mathrm{O}_{2}$ induction systems. Investigated EOs reduced the DPPH radical formation $\left(\mathrm{IC}_{50}=3.82 \mu \mathrm{g} / \mathrm{mL}\right.$ for rosemary and $1.78 \mu \mathrm{g} / \mathrm{mL}$ for sage) in a dose-dependent manner [60].

Finally, in a more recent study, antioxidant activity and chemical composition of the volatile oils of nine populations of six species from Albania, including S. officinalis, were investigated. More to the point, the EOs were obtained by hydrodistillation and their analyses were performed by GC-MS. The major constituents for S. officinalis were camphor (40.2, 47.8, 45.9\%), $y$-thujone (19.2, 22.2, 13.7\%), eucalyptol (5.4, 2.6, 6.0\%), camphene $(5.8,6.1$, $3.9 \%$, borneol $(2.1,2.9,5.7 \%)$, and bornyl acetate $(3.3,1.4$, $5.6 \%$ ) for samples originating from Tepelena, Tirana, and Vlora, respectively. The EOs were also tested for their free radical scavenging activity using the following in vitro assays: (i) interaction with the free stable radical of DPPH and (ii) inhibition of linoleic acid peroxidation with 2,2'-azobis-2-methyl-propanimidamide dihydrochloride (AAPH). The results showed significant antioxidant activity for sage [61].

In summary, there are many comparative studies of different Salvia species and varieties, comparing their in vitro antioxidant activity after extraction of their phenolic components with various extraction methods [supercritical $\mathrm{CO}_{2}$ extraction, Soxhlet (hexane) extraction, maceration with ethanol, optimized pressurized liquid extraction, etc.] and solvents (ethyl acetate, ethanol, methanol, acetone, etc.). Total phenolic content is measured by the FC assay, whereas HPLC, LC/MS, GC/MS, and NMR are used for the determination of the specific phenolic constituents. Methods commonly used for measurement of the in vitro antioxidant activity of Salva sp. extracts are the spectrophotometrical methods DPPH, TEAC/ABTS, ORAC, and FRAP. DPPH is also combined with TLC in some studies. Other methods rarely used are xanthine oxidase, lipoxygenase and acetylcholinesterase enzymes inhibition, $\beta$-carotene-linoleic acid assay, lipid peroxidation activity, phosphatidylcholine liposome oxidation, nitric oxide scavenging, hydrogen peroxide scavenging, Rancimat test, metmyoglobin test, Briggs-Rauscher reaction, $\beta$-carotene bleaching, QUENCHER method, and deoxyribose assays for the scavenging of hydroxyl radical, GSH content, MDA content, and (CAT-like) and superoxide dismutase (SOD-like) activities. Sage extract EOs contain rosmarinic acid (the dominant naturally occurring compound of sage), carnosic acid, carnosol, $\alpha$-thujone, $\gamma$-thujone, camphor, 1,8-cineole, eucalyptol, camphene, borneol, bornyl acetate, linalool, and terpinene, whereas other components usually found in sage are chlorogenic acid, caffeic acid, ferulic acid, coumaric acid, catechin, vanillin, quercetin, apigenin, scutellarein, rutin, rosmanol, and luteolin. The antioxidant activity, as measured by the scavenging of the free radical DPPH, is positively correlated with total phenolic and flavonoids content of sage extracts and EOs, whereas there was one study in which it was also correlated with the extracted polysaccharides. Different sage varieties and different extraction methods result in different phenolic component concentrations and antioxidant activity.

\section{Antioxidant activity of sage: in vitro cell culture studies}

Many studies for the protective effect of sage components in cultured cells after induction of oxidative stress have been performed. DNA damage is a major effect of oxidative stress. In this aspect, a substantial study from Ramos and co-workers evaluated the effects of the water extracts of three Salvia species, S. officinalis, S. fruticosa, and Salvia lavandulifolia, and their major phenolic constituents rosmarinic acid and luteolin-7-glucoside (L-7-G), on DNA protection in Caco-2 and HeLa cells exposed to oxidative agents, and on DNA repair in Caco- 2 cells. In fact, a comet assay was used to measure DNA damage and repair capacity. The final concentration of each sage extract was $50 \mu \mathrm{g} / \mathrm{mL}$, and concentrations of rosmarinic acid and L-7-G were 50 and $20 \mu \mathrm{M}$, respectively. After a short incubation (2 h), L-7-G protected DNA in Caco-2 cells from damage induced by $\mathrm{H}_{2} \mathrm{O}_{2}(75 \mu \mathrm{M})$. Moreover, after a long incubation period ( $24 \mathrm{~h}$ ), S. fruticosa, rosmarinic acid, and L7-G exerted protective effects in Caco-2 cells. In HeLa cells, S. officinalis, $\mathrm{S}$. fruticosa, and rosmarinic acid protected against damage induced by $\mathrm{H}_{2} \mathrm{O}_{2}$ after $24 \mathrm{~h}$ of incubation. Assays of DNA repair showed that S. officinalis, S. fruticosa, and L-7-G increased the rate of DNA repair (rejoining of strand breaks) in Caco-2 cells treated with $\mathrm{H}_{2} \mathrm{O}_{2}$. The incision activity of a Caco-2 cell extract on a DNA substrate containing specific damage (8-oxoGua) was also measured to evaluate effects on base excision repair (BER) activity. Preincubation for $24 \mathrm{~h}$ with $\mathrm{S}$. officinalis and L-7-G had a BER inductive effect, increasing incision activity in Caco-2 cells [62]. In another study on the same Salvia species by Ramos and co-workers, the genotoxic effect of $\mathrm{H}_{2} \mathrm{O}_{2}$ was examined in two colon cell lines (HCT15 and CO115). DNA damage was assessed by the comet assay with and without lesion-specific repair enzymes. Protective effects of extracts of the three Salvia species mentioned above against DNA damage induced by $\mathrm{H}_{2} \mathrm{O}_{2}$ were also determined. S. officinalis and SF protected against oxidative DNA damage in HCT15 cells. Data showed that sage tea protected colon cells against oxidative DNA damage [63].

In a previous study, the effects of plant extracts from rosemary (R. officinalis L.), oregano (O. vulgare L.), sage (S. officinalis L.), and echinacea (Echinacea purpurea L.) on the viability, membrane integrity, antioxidant status, and DNA integrity of Caco-2 cells, and the cytoprotective and genoprotective effects of these plant extracts against oxidative stress in Caco-2 cells, were determined. Cell membrane integrity was assessed by the lactate dehydrogenase release assay. Moreover, viability was determined by the neutral red uptake assay (NRUA) and the concentration of compound that resulted in $50 \%$ cell death $\left(\mathrm{IC}_{50}\right)$ was calculated. Antioxidant status of the cells was assessed by measuring GSH content, catalase activity, and SOD activity. To examine plant extracts' cytoprotective and genoprotective effects, Caco-2 cells were pretreated with each plant extract for $24 \mathrm{~h}$ followed by exposure to $\mathrm{H}_{2} \mathrm{O}_{2}$. DNA damage was assessed by the comet assay and cell injury was determined by the NRUA. Interestingly, sage was the only plant extract to affect the antioxidant status of the cells by increasing GSH content. Sage, oregano, and rosemary protected against $\mathrm{H}_{2} \mathrm{O}_{2}$-induced DNA damage (olive tail moment and percentage tail DNA), whereas protection against $\mathrm{H}_{2} \mathrm{O}_{2}$-induced cytotoxicity was afforded by sage only [64].

Furthermore, the cytoprotective effects of two sage extracts (a water and a methanolic extract) from $S$. officinalis against tertbutyl hydroperoxide (t-BHP)-induced toxicity in HepG2 cells was evaluated. According to this study, the most abundant phenolic compounds present in the extracts were rosmarinic acid and 
luteolin-7-glucoside. Both extracts, when coincubated with the toxicant, significantly protected HepG2 cells against cell death. Notably, the methanolic extract, with a higher content of phenolic compounds than the water extract, conferred better protection in this in vitro model of oxidative stress for liver cells. Both extracts, tested in a concentration that protects against $80 \%$ cell death $\left(\mathrm{IC}_{80}\right)$, significantly prevented t-BHP-induced lipid peroxidation and GSH depletion, but not DNA damage assessed by the comet assay. It should be noted that the ability of sage extracts to reduce t-BHP-induced GSH depletion by $62 \%$ was probably the most relevant contributor to the observed cytoprotection. In addition, a good correlation between the above cellular effects of sage and the effects of their main phenolic compounds was found. When incubated alone for $5 \mathrm{~h}$, sage extracts induced an increase in basal GSH levels of HepG2 cells, which indicated an improvement of the antioxidant potential of the examined cells. The authors suggested that compounds present in sage extracts other than phenolics could also contribute to this effect [65]. In another cell viability model of PC12 cells, Gong and co-workers investigated the antioxidant activity of salvianolic acids extracted from Salvia plants after treatment with $\mathrm{H}_{2} \mathrm{O}_{2}$. The protection of $\mathrm{PC} 12$ cells from injury induced by $\mathrm{H}_{2} \mathrm{O}_{2}$ by salvianolic acid $\mathrm{Y}$ (TSL 1) was $54.2 \%$, which was significantly higher than that of salvianolic acid B (35.2\%) [66].

Kozics and co-workers studied the composition and quantitative estimation of plant extracts from $S$. officinalis and T. vulgaris as well as the protective effects of plant extracts against $\mathrm{H}_{2} \mathrm{O}_{2}$ and 2,3-dimethoxy-1,4-naphthoquinone-induced DNA damage and the levels of enzymatic and non-enzymatic antioxidants (SOD, glutathione peroxidase-GPx, glutathione) in human HepG2 cells. To measure antioxidant activity of plant extracts, DPPH, FRAP, and ABTS assays were used. The results showed that the oxidant-induced DNA lesions were significantly reduced in cells pretreated with the plant extracts studied. The observed DNA protective activity could be ascribed to both the elevation of GPx activity in cells pretreated with $S$. officinalis and $T$. vulgaris and the antioxidant activity of $S$. officinalis and T. vulgaris [67].

Interestingly, the in vitro neuroprotective activity of Salvia lavandulifolia Vahl., known as "Spanish sage", EOs, obtained from plants at different phenological stages (vegetative and flowering phases) and plants grown at different densities, against $\mathrm{H}_{2} \mathrm{O}_{2}$-induced oxidative stress in PC12 cells was evaluated. Moreover, the effect on cell viability and morphology, lipid peroxidation, GSH/ GSSG ratio, intracellular ROS levels, antioxidant enzymes [CAT, SOD, glutathione reductase (GR), GPx, Heme oxygenase-1 (HO$1)$ ], and apoptotic enzymes was investigated. Comparing with $\mathrm{H}_{2} \mathrm{O}_{2}$-treated PC12 cells, pretreatments with EOs samples attenuated morphological changes and loss of cell viability, decreased MDA levels and intracellular ROS production, and increased the GSH/GSSG ratio. Moreover, Spanish sage increased the antioxidant status, as evidenced in an increase of antioxidant enzyme activity and protein expression, and inhibited caspase- 3 activity. Collectively, the samples of EOs obtained with the highest densities of planting and at flowering phase exerted a major neuroprotective activity. These findings demonstrated that S. lavandulifolia EOs may have therapeutic value for the prevention and treatment of neurodegenerative diseases associated with oxidative stress-induced neuronal injury [68]. The same research group investigated the composition of the EOs of S. lavandulifolia and the potential in vitro cytoprotective and antioxidant activities of its major compounds, $\alpha$-pinene and 1,8-cineole, against $\mathrm{H}_{2} \mathrm{O}_{2}$-induced oxidative stress in the U373-MG astrocytes cell line. Chemical composition was analyzed by GC, antioxidant capacity was measured using the ORAC assay, and cytoprotective activity was evaluated using the MTT assay (for cell viability) (range of concentrations: 10-400 $\mathrm{MM}$ ), DCFH-DA (dichloro-dihydro-fluorescein diacetate) assay (for intracellular ROS generation), TBARS assay (for lipid peroxidation), and spectrophometric techniques and Western blot (for enzymatic activity and protein expression, respectively) at 10 and $25 \mu \mathrm{M}$. $\alpha$-Pinene (18.39\%) and 1,8-cineole (19.57\%) were identified as major compounds in S. lavandulifolia EO. Pretreatment with these monoterpenes protected U373-MG cells against $\mathrm{H}_{2} \mathrm{O}_{2}$-induced oxidative injury by attenuating the loss of cell viability ( $\mathrm{IC}_{50}$ of $79.70 \mu \mathrm{M}$ for $\alpha$-pinene and $66.23 \mu \mathrm{M}$ for 1,8-cineole) and cell morphology, inhibiting ROS production (the most active compound was 1,8-cineole by decreasing the ROS production over $30-45 \%$ at 10 and $25 \mu \mathrm{M}$ ) and lipid peroxidation, and increasing the endogenous antioxidant status (glutathione levels and CAT, SOD, GR, GPx, and HO- 1 activity and protein expression) [69].

In a previous study, the ability of dimethyl lithospermate (DML), isolated from Salvia miltiorrhiza, to scavenge peroxynitrite $\left(\mathrm{ONOO}^{-}\right)$, a reactive oxidant formed from superoxide and nitric oxide that can readily oxidize cellular components, including essential protein, non-protein thiols, and DNA, and to protect cells against reactive species and $\mathrm{ONOO}^{-}$, was investigated. The data obtained showed that DML could efficiently scavenge native $\mathrm{ONOO}^{-}$as well as $\mathrm{ONOO}^{-}$derived from the $\mathrm{ONOO}^{-}$donor 3-morpholinosydnonimine hydrochloride. Spectrophotometric analysis revealed that $\mathrm{DML}$ led to decreased $\mathrm{ONOO}^{-}$-mediated nitration of tyrosine through electron donation. DML significantly inhibited nitration of BSA by $\mathrm{ONOO}^{-}$in a dose-dependent manner. DML also manifested cytoprotection from cell damage induced by $\mathrm{ONOO}^{-}$ [70].

Brahmi and co-workers investigated the hydroalcoholic extracts of 11 Algerian medicinal and aromatic plants, including S. officinalis, for their antiradical and antioxidant properties in cell-free systems. When the cytotoxic effects of low and antioxidant doses of each extract were evaluated towards SK-N-BE(2)C neuronal and HepG2 hepatic cell lines, it was observed that all the extracts weakly affected the metabolic redox activity of the tested cell lines [71].

Vaško and co-workers investigated the effect of extracts from known and frequently used plants as part of diet, food seasoning, medicinal tea, and sweetener, including sage, at different concentrations, concerning the ability to scavenge free radicals, to affect antioxidant enzymes, and, finally, regarding the survival of cancer cell lines. They found that the extract concentration of about $100 \mu \mathrm{g} / \mathrm{mL}$ was more indicative in the assessment of all parameters investigated. In contrast, the range of operating concentrations for sage mainly presented no significant effects against reactive oxygen and nitrogen species, whereas a significantly reduced activity of GPx was detected [72]. 
Finally, Chohan and co-workers investigated the anti-inflammatory activity following cooking and in vitro digestion of the common culinary herbs rosemary, sage, and thyme, and the relationship between their anti-inflammatory activity, polyphenol content, and antioxidant capacity. The anti-inflammatory activity of uncooked $(\mathrm{U})$, cooked $(\mathrm{C})$, both cooked and in vitro digested (C\&D), and standardized (STD, $30 \mathrm{mg} / \mathrm{mL}$ ) culinary herbs was assessed by measuring their effect on interleukin 8 (IL-8) release from stimulated human peripheral blood lymphocytes (PBLs) and Caco-2 cells. TEAC and TPC of the herbs were also determined. There was a significant decrease in IL-8 release from PBLs stimulated with $\mathrm{H}_{2} \mathrm{O}_{2}$ incubated with $\mathrm{U}, \mathrm{C}, \mathrm{C} \& D$, and STD herbs and from Caco- 2 cells stimulated with TNF $\alpha$ incubated with C\&D and STD herbs. PBLs preincubated with $C \& D$ herbs prior to stimulation with $\mathrm{H}_{2} \mathrm{O}_{2}$ or TNF $\alpha$ caused a significant inhibition in IL-8 release. The significant correlations between TEAC and estimated phenolic content and the anti-inflammatory activity supported evidence for a possible contributory role of polyphenols to the anti-inflammatory activity of the culinary herbs investigated [73].

In summary, sage components have shown cytoprotective and genoprotective effects in cells in culture after oxidative stress induction (by $\mathrm{H}_{2} \mathrm{O}_{2}$ or t-BHP treatment). Phenolic components such as rosmarinic acid, luteolin-7-glucoside, $\alpha$-pinene, 1,8-cineole, and salvianolic acids have been found to offer protection to cells from the DNA damage effects of oxidative stress. Cells commonly used in these studies were Caco-2, HeLa, SK-N-BE(2)C neuronal cell line, HepG2 hepatic cell line, PC12, U373-MG astrocytes cell line, human PBLs, and the colon cancer cell lines HCT15 and C0115. Additionally, the viability, membrane integrity, and antioxidant status of cultured cells were studied. Cell membrane integrity was assessed by the lactate dehydrogenase release assay, whereas viability was determined by NRUA and MTT assays. Antioxidant status of the cells was assessed by measuring intracellular ROS levels, peroxynitrite scavenging, lipid peroxidation, DPPH, FRAP, ABTS, TBARS, and ORAC assays, GSH/GSSG ratio or GSH content, and CAT, SOD, GR, GPx, and HO-1 activity and protein expression. In these studies, cells were pretreated with the extract, or coincubated with the extract and the oxidant. Extracts obtained from different extraction methods and containing different concentrations of phenolic components have shown different cytoprotective and genoprotective activity. Expression of apoptotic proteins like caspase-3, and release of anti-inflammatory proteins like IL- 8 were also reduced by sage extracts. A positive correlation between these protective effects and their main phenolic compounds was recorded.

\section{Antioxidant activity of sage: in vivo animal studies}

There is a series of different in vivo animal studies investigating the antioxidant activity and health benefits of sage varieties. In a recent study, Güzel and co-workers evaluated the in vivo wound healing potential, in vitro antioxidant activities, and total phenolic and flavonoid contents of the aerial parts of two endemic taxa, Salvia kronenburgii Rech. f. (SK) and Salvia euphratica Montbret, Aucher \& Rech. f. var. euphratica (SE). Two different concentrations $[0.5 \%$ and $1 \%(\mathrm{w} / \mathrm{w})]$ of ethanol extracts were investigated in incision and excision wound models on streptozotocin-induced diabetic rats using biomechanical, biochemical, histopathological, macroscopic, and genotoxic methods for 7 and 14 days. Antioxidant capacities and total phenolic and flavonoid contents of both extracts were detected using DPPH, Folin-Ciocalteu, and $\mathrm{Al}\left(\mathrm{NO}_{3}\right)_{3}$ methods, respectively. In fact, SK ointment at 0.5 and $1 \%(w / w)$ concentrations and SE ointment at $1 \%(w / w)$ concentration showed 99.9, 99.5, and 99.7\% contraction, respectively, for excision wounds, and both SK and SE ointments at $1 \%(w / w)$ concentration showed 99.4 and $99.2 \%$ contractions for incision wounds. Moreover, SE ointment on day 7 and SK ointment on day 14 significantly reduced oxidative damage to DNA when compared to the control. Antioxidant capacities and total phenolic and flavonoid contents of SE and SK were 87.08\%, $76.21 \mu \mathrm{g} \mathrm{GAE} / \mathrm{mg}, 43.43 \mu \mathrm{g}$ $\mathrm{QE}$ (quercetin equivalents)/mg, and $72.17 \%, 41.81 \mu \mathrm{g} \mathrm{GAE} / \mathrm{mg}$, $33.62 \mu \mathrm{g} \mathrm{QE} / \mathrm{mg}$, respectively. SK and SE exerted strong wound healing effects, while SK was found to be more effective than SE at both 7 and 14 days [74].

In another study, Zhou and co-workers investigated salvianolic acid $B(S B)$, an antioxidant derived from Salvia militarize and one of the most widely used herbs in traditional Chinese medicine. SB is a potent antioxidant that has been well documented as a scavenger of oxygen free radicals and has been used for the prevention and treatment of atherosclerosis-associated disorders. To explore its potential therapeutic effects in treating radiation damage, in this study, mice were treated with SB at different doses of 5, 12.5, and $20 \mathrm{mg} / \mathrm{kg}$, subsequent to receiving $\gamma$-irradiation. The effects of SB on peripheral blood, bone marrow nucleated cells, spleen and thymus indices, and oxidation resistance were evaluated in both radiated mice and control groups. The results indicated that SB significantly increased the counts of peripheral white blood cells, red blood cells, and platelets. The number of nucleated cells in the bone marrow and the level of protein increased as well. In addition, improved spleen and thymus indices in the bone marrow were observed. SB treatment additionally reversed the deterioration of both the thymus and spleen indices, which was associated with increased serum SOD activity and decreasing MDA levels via a nuclear factor (erythroid-derived 2)-like 2 protein/BTB and CNC homology 1 (Nrf2/Bach1)-mediated antioxidant effect. Furthermore, ROS levels and apoptotic protein Bax expression were also suppressed by SB [75].

In another study, aqueous extracts of a few medicinal plants traditionally used in Portugal (agrimony, sage, savory, and raspberry) were assayed for their effects upon hepatic oxidative stress in mice. For this purpose, mice ingested extracts in aqueous form (or water, used as the control) for 4 weeks, and damage to lipids, proteins, and DNA was evaluated by oxidative cell biomarkers by the end of that period. Levels of hepatic glutathione and activities of enzymes involved in metabolism were also determined. Finally, CAT and SOD activities were quantified, as these enzymes play a crucial role in antioxidant defense. All plants led to a decrease in CAT activity, whereas all but sage also produced a decrease in SOD activity. With regard to glutathione levels and activities of enzymes involved in its metabolism, the aforementioned extracts exhibited different effects. In general, raspberry appeared to be the most promising extract, followed by savory, sage, and agrimony, sorted by decreasing performance in protection [76].

The potential hepatoprotective and in vivo antioxidant efficacy of sage $\mathrm{EO}$ in Co-amoxiclav-induced hepatotoxicity in rats was in- 
vestigated by El-Hosseiny and co-workers. At first, sage EOs was hydrodistilled from the aerial parts of $S$. officinalis and its compositional analysis was characterized by GC/MS. Then, rats were treated singly or concomitantly with Co-amoxiclav and sage EO for a period of 7 days. The major components of sage oil as identified by GC-MS were 1,8-cineole, $\beta$-pinene, camphor, $\beta$-caryophyllene, $\alpha$-pinene, and $\alpha$-caryophyllene comprising $26.3,14.4,10.9,7.8$, 6 , and $2.5 \%$, respectively. The in vivo exposure of rats to Co-amoxiclav resulted in hepatotoxicity, biochemically evidenced by the significant elevation of serum aspartate aminotransferase (AST), alanine transaminase (ALT), alkaline phosphatase (ALP), $\gamma$-glutamyl-transferase $(\gamma-G T)$, and total bilirubin and histologically conveyed by hydropic, inflammatory, and cholestatic changes in the rats' liver. Oxidative stress mediated the hepatic injury as indicated by the significant escalation in lipid peroxidation, as well as the significant depletion of both the glutathione level and glutathione-dependent enzyme activities. Interestingly, the concomitant administration of sage EO with Co-amoxiclav exerted a hepatoprotective effect via induction of an in vivo antioxidant defense response, eventually regressing, to some extent, the hepatoarchitectural changes induced by Co-amoxiclav. The above results suggested that sage EO may be considered a potential candidate for counteracting hepatic injury associating Co-amoxiclav, and this effect may be in part related to the complexity of its chemical composition [77].

Hasaein and co-workers hypothesized that chronic administration of S. officinalis extract $(400,600$, and $800 \mathrm{mg} / \mathrm{kg}$, p. o.) and its principal constituent, rosmarinic acid, could affect passive avoidance learning (PAL) and memory in streptozocin-induced diabetic and nondiabetic rats. They also explored hypoglycemic and antioxidant activities of $S$. officinalis extracts as the possible mechanisms. Treatments were begun at the onset of hyperglycemia and PAL was assessed 30 days later. A retention test was performed $24 \mathrm{~h}$ after training. At the end, animals were weighed, and blood samples were drawn for further analysis of glucose and oxidant/antioxidant markers. Diabetes induced deficits in acquisition and retrieval processes. Interestingly, S. officinalis extract (600 and $800 \mathrm{mg} / \mathrm{kg}$ ) and rosmarinic acid reversed learning and memory deficits induced by diabetes and improved cognition of healthy rats. It should be noted that while the dose of $400 \mathrm{mg} / \mathrm{kg}$ had no effect, the higher doses and rosmarinic acid inhibited hyperglycemia and lipid peroxidation, as well as enhanced the activity of the antioxidant enzymes SOD and CAT. Therefore, the sage extract prevented diabetes-induced acquisition and memory deficits through inhibiting hyperglycemia and lipid peroxidation, as well as by enhancing antioxidant defense systems [78].

The influence of four different concentrations of $S$. officinalis EO on animal health was compared by Placha and co-workers. A total of 50 laying strain chicks were randomly divided at the day of hatching into five dietary treatment groups. The control group was treated with the basal diet (BD), and the other four experimental groups contained BD supplemented with $0.1,0.25,0.5$, $1.0 \mathrm{~g}$ S. officinalis EO/kg diet, respectively. Notably, $0.1 \mathrm{~g} / \mathrm{kg}$ EO increased GPx activity in the duodenal mucosa, liver and kidney, phagocytic activity (PA) in blood, and transepithelial electrical resistance (TEER) in duodenal tissue, and decreased MDA concentration in plasma and liver. Moreover, $0.25 \mathrm{~g} / \mathrm{kg}$ EO increased GPx in the liver, total antioxidant status (TAS) in plasma, PA in blood, and TEER in duodenal tissue. As a conclusion, lower concentrations of EO were found to improve the animals' health status [79].

Horváthová and co-workers carried out a study to ascertain whether liver cells of experimental animals drinking extracts of sage could manifest increased resistance against oxidative stress. Adult Sprague-Dawley rats were divided into 7 groups and they drank sage extracts for 2 weeks. At the end of the drinking period, blood samples were collected for determination of liver biochemical parameters, and hepatocytes were isolated to analyze (i) oxidatively generated DNA damage, (ii) activities of antioxidant enzymes (SOD, GPx), and (iii) glutathione content. Intake of sage had no effect either on the basal level of DNA damage or on the activity of SOD in rat hepatocytes and did not alter the biochemical parameters of blood plasma. Simultaneously, GPx activity was significantly increased and the level of DNA damage induced by oxidants was decreased. Moreover, sage extract was able to start up the antioxidant protection expressed by increased glutathione content [80].

In another study, the effects of methanolic extracts of leaves of S. officinalis on antioxidant enzymes such as SOD, GPx, and CAT activities and on the levels of plasma lipids profiles such as triglycerides (TG), total cholesterol (TC), high-density lipoproteins (HDL), low-density lipoproteins (LDL), and very low-density lipoproteins (VLDL) in Alloxan diabetic Wistar rats were evaluated. In comparison with diabetic control rats, in diabetic-treated rats, sage extract increased SOD activity by 60 and 33\% respectively, and decreased TG (40\%) and LDL (30\%). Metformin exhibited mild antioxidant and hypolipidemic properties. These results supported evidence that $S$. officinalis could be beneficial in the control of diabetes by noticeable antioxidant and hypolipidemic properties [81].

In addition, anti-inflammatory and antioxidant activity of S. officinalis in alipopolysaccharide (LPS)-induced experimental inflammation model was investigated. In this study, 42 female Wistar albino rats, aged 4 to 5 years old, were divided into 6 groups. Three groups were intraperitoneally administered $1 \mathrm{mg} / \mathrm{kg}$ LPS and, $24 \mathrm{~h}$ after LPS injection, 10 and $30 \mathrm{mg} / \mathrm{kg} \mathrm{S}$. officinalis extract were treated orally to the intervention groups. Pulmonary and hepatic 18F-fluoro-deoxy-D-glucose (18F-FDG) uptake was calculated to determine the status of inflammation by an $18 \mathrm{~F}$-fluorodeoxy-D-glucose-positron emission tomography (18FDG-PET) scan. Antioxidant enzyme activities and nitric oxide and MDA levels were determined. Serum nuclear factor-kappa B (NF-kB) and TNF- $\alpha$ levels were also assessed. As a result, lung and liver $18 \mathrm{~F}-\mathrm{FDG}$ uptake was found to be higher in the inflammation group than the control one. MDA levels in erythrocytes and all tissue samples (liver, lung, and kidney) were found to be significantly higher compared to the treatment groups. SOD, CAT, and GPx activities of the inflammation group in the liver, lung, kidney tissues, and erythrocytes were determined. Both SOD and CAT activities were significantly lower in groups treated with $S$. officinalis extract. Moreover, enhanced nitric oxide, NF- $\kappa B$, and TNF- $\alpha$ levels were found in the inflammation group [82].

Sönmez and co-workers evaluated the potential effects of dietary supplementation of sage (S. officinalis), mint (Mentha spicata), and thyme (T. vulgaris) oils on growth performance, lipid peroxi- 
dation level (MDA), and liver antioxidant enzyme activities [SOD, CAT, glucose-6-phosphate dehydrogenase (G6PD), GR, glutathione-S-transferase (GST), and GPx] in rainbow trout (Oncorhynchus mykiss) juveniles. For this purpose, triplicate groups of rainbow trout were fed daily ad libitum with diets containing sage, mint, and thyme oils at 500, 1000, and $1500 \mathrm{mg} / \mathrm{kg}$ for 60 days. While weight gain percentage of fish fed the diets containing sage and thyme oils was significantly higher than the control group, that of fish fed mint oil was lower. Similarly, the specific growth rate was found to be the highest in all groups of the sage and thyme oil feeding, and the lowest in the mint groups. Moreover, the feed conversion ratio was significantly higher in the mint oil administered groups. Survival rate was also significantly reduced in the fish fed the diet containing mint oil. It was observed that SOD, G6PD, and GPx activities were significantly increased in liver tissues of all the treated fish groups compared to that of the control diet-fed group. However, CAT, GST, and GR activities were significantly decreased in experimental diet-fed fish groups at the end of the experiment. On the other hand, a significant reduction was found in MDA levels in the fish fed the diets with sage and thyme oils compared to the control and mint diets on the 30th and 60th days of the experiment. Overall, dietary inclusion of sage and thyme oils was effective in enhancing rainbow trout growth, reducing MDA levels, and decreasing antioxidant enzyme activities at a low level $500 \mathrm{mg} / \mathrm{kg}$ diet. Thus, they could be used as important feed supplements for rainbow trout production [83].

In another study, the biosafety and bioactivity (antioxidant potential) of a traditional water infusion (tea) of common sage (S. officinalis) in vivo in mice and rats were evaluated by quantification of plasma transaminase activities and liver GST and GR enzyme activities. The replacement of water by sage tea for 14 days in the diet of rodents did not affect the body weight or food consumption, and did not induce liver toxicity. On the other hand, a significant increase of liver GST activity was observed in both rats (24\%) and mice $(10 \%)$ treated with sage. The antioxidant potential of sage tea drinking was also studied in vitro in a model using rat hepatocytes in primary culture. The replacement of drinking water with sage tea in the rats used as hepatocyte donors resulted in an improvement of the antioxidant status of rat hepatocytes in primary culture, namely, a significant increase in GSH content and GST activity after $4 \mathrm{~h}$ of culture. When these hepatocyte cultures were exposed to 0.75 or $1 \mathrm{mM} \mathrm{t}$-BHP for $1 \mathrm{~h}$, some protection against lipid peroxidation and GSH depletion was conferred by sage tea drinking. However, the cell death induced by t-BHP as shown by lactate dehydrogenase (LDH) leakage was not different from that observed in cultures from control animals. This study indicated that the compounds present in this sage preparation may contain interesting bioactivities, which could improve the liver antioxidant potential [84].

Finally, a pilot trial (non-randomized crossover trial) with six healthy female human volunteers (aged 40-50) was designed to evaluate the beneficial properties of sage tea (S. officinalis) consumption on blood glucose regulation, lipid profile, and transaminase activity in humans. Effects of sage consumption on erythrocyte SOD and CAT activities and on Hsp70 expression in lymphocytes were also evaluated. A 4-week sage tea treatment had no effects on plasma glucose. An improvement in lipid profile was

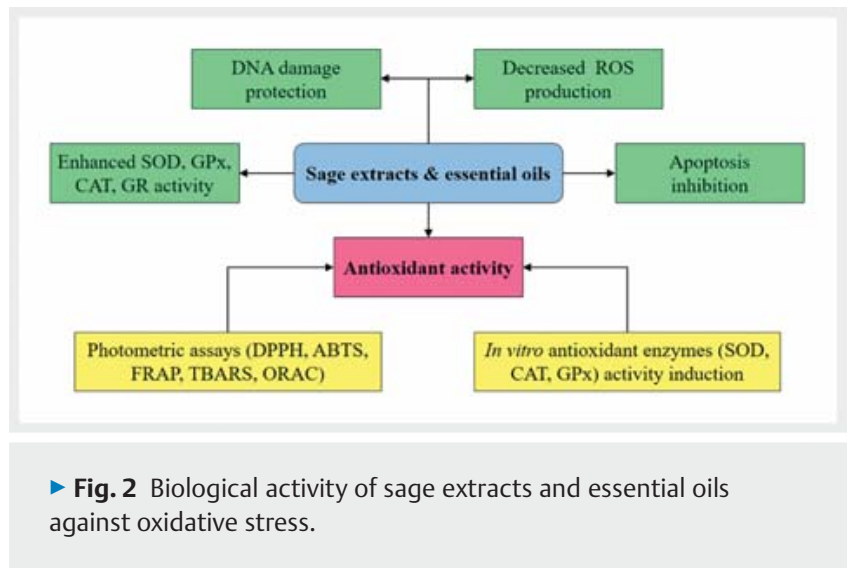

observed with lower plasma LDL cholesterol and total cholesterol levels, as well as higher plasma HDL cholesterol levels during and 2 weeks after treatment. Sage tea also increased lymphocyte Hsp70 expression and erythrocyte SOD and CAT activities. No hepatotoxic effects or other adverse effects were observed [85].

In summary, many in vivo animal studies assessing the potential beneficial effects of sage, combined with in vitro studies on their antioxidant activity and the total phenolic and flavonoid contents, have been performed. Animal models commonly used were wound models on streptozotocin-induced diabetic rats, hepatic oxidative stress-induced mice, chickens, Sprague-Dawley rats, Alloxan diabetic Wistar rats, and inflammation-inducing Wistar albino rats. Animals were fed with sage extracts or EOs after inducing oxidative stress, and parameters such as antioxidant enzymes activity (SOD, CAT, GPx, GST, GR, G6PD), AST, ALT, ALP, and $\gamma$-GT levels, GSH, ROS, and MDA levels, and DNA damage were measured. Additionally, there was a pilot trial including humans fed with sage extracts. All sage extracts, EOs, or tea preparations resulted in antioxidant activity, anti-inflammatory effects, and general improvement of health.

\section{Conclusions}

The sage plant is rich in secondary metabolites (polyphenols, flavonoids, terpenes), indicating significant antioxidant capacity. Different methods for the determination of this antioxidant activity have shown variation depending on the extraction conditions, the in vitro or in vivo model used, and/or the concentration of bioactive components found in the extract. In many studies, the investigation of the antioxidant activity of sage was performed by the use of photometric assays (DPPH, ABTS, FRAP, TBARS, ORAC) or methods that determined antioxidant enzyme (SOD, CAT, GPx) activity ( $\vee$ Fig. 2 ). These assays were combined with the determination of TPC by FC or the specific phenolic components by chromatographic methods. The antioxidant activity determined was usually correlated with the concentration of specific phenolic components, like caffeic acid, rosmarinic acid, coumaric acid, carnosic acid, catechin, quercetin, rosmanol, epirosmanol, etc.

EOs seem to play a key role in the antioxidant activity of sage. Many studies have unraveled their specific role by using DPPH, TEAEC, ABTS, FRAP, or $\beta$-carotene bleaching assays ( $\bullet$ Fig. 2). 
Components found in EOs mainly playing this antioxidant activity were $\alpha$-thujone, $\beta$-thujone, camphor, linalool, 1,8-cineole, and others.

In addition to cell-free system studies, cell cultures of cancer or primary cells were also used in order to investigate the protective role of sage extracts after inducing oxidative stress, usually by $\mathrm{H}_{2} \mathrm{O}_{2}$ treatment. Cells were pretreated with the sage extract, and then oxidative stress was inducted to cells. The cytoprotective and antioxidant activity of sage extracts, especially of phenolic components like luteolin-7-glucoside, $\alpha$-pinene, rosmarinic acid, and 1,8-cineole, was determined by the inhibition of DNA damage, the enhanced activity of SOD, GPx, CAT, and GR, the reduced production of ROS as measured by DCFH-DA, and the inhibition of apoptosis, as measured by MTT and the reduced protein levels of apototic proteins ( $\bullet$ Fig. 2).

Moreover, sage antioxidant properties were also assessed by in vivo animal models. Animals were treated with or ingested sage extracts, and serum levels of antioxidant enzymes (SOD, CAT), levels of ALT, AST, ALP, $\gamma$-GT, MDA reduction, DNA damage protection, and wound healing properties were determined.

Alarmingly enough, most literature data concerning the antioxidant activity of sage extracts and their bioactive components have currently been restricted to a great number of in vitro studies and some animal studies, whereas no adequate human studies have been performed so far. The promising in vitro data and the results produced by animal studies are surely substantial and useful, however, they should not be extrapolated to human situations. In this aspect, a strong limitation that should be taken into careful consideration is the already well-known low oral bioavailability of the bioactive components of sage, e.g., polyphenols. This fact means that although these bioactive components show strong in vitro antioxidant activity, this antioxidant activity may not be exerted in human situations due to the cell permeability barrier of the small intestine. Beyond the low oral bioavailability, potential metabolization of sage bioactive components by the human liver should also been taken into account. In view of the above considerations, there is a strong demand for future human clinical studies in order to confirm the potential antioxidant properties of sage and its bioactive components in human.

\section{Conflict of Interest}

The authors declare that they have no conflict of interest.

\section{References}

[1] Ghorbani A, Esmaeilizadeh M. Pharmacological properties of Salvia officinalis and its components. J Tradit Complement Med 2017; 7: 433-440

[2] Berdowska I, Zieliński B, Fecka I, Kulbacka J, Saczko J, Gamian A. Cytotoxic impact of phenolics from Lamiaceae species on human breast cancer cells. Food Chem 2013; 141: 1313-1321

[3] Poulios E, Giaginis C, Vasios GK. Current advances on the extraction and identification of bioactive components of sage (Salvia spp.). Curr Pharm Biotechnol 2019; 20: 845-857

[4] Ray PD, Huang BW, Tsuji Y. Reactive oxygen species (ROS) homeostasis and redox regulation in cellular signaling. Cell Signal 2012; 24: 981-990

[5] McCord JM. The evolution of free radicals and oxidative stress. Am J Med 2000; 108: 652-659
[6] Circu ML, Aw TY. Reactive oxygen species, cellular redox systems, and apoptosis. Free Radic Biol Med 2010; 48: 749-762

[7] Guerriero G, Berni R, Muñoz-Sanchez JA, Apone F, Abdel-Salam EM, Qahtan AA, Alatar AA, Cantini C, Cai G, Hausman JF, Siddiqui KS, Hernández-Sotomayor SMT, Faisal M. Production of plant secondary metabolites: examples, tips and suggestions for biotechnologists. Genes (Basel) 2018; 9: E309

[8] Tungmunnithum D, Thongboonyou A, Pholboon A, Yangsabai A. Flavonoids and other phenolic compounds from medicinal plants for pharmaceutical and medical aspects: an overview. Medicines 2018; 5: E93

[9] Schwarz K, Ternes W. Antioxidative constituents of Rosmarinus officinalis and Salvia officinalis. II. Isolation of carnosic acid and formation of other phenolic diterpenes. Z Lebensm Unters Forsch 1992; 195: 99-103

[10] Santos-Gomes PC, Seabra RM, Andrade PB, Fernandes-Ferreira M. Determination of phenolic antioxidant compounds produced by calli and cell suspensions of sage (Salvia officinalis L.). J Plant Physiol 2003; 160: 10251032

[11] Živković ], Ristić M, Kschonsek J, Westphal A, Mihailović M, Filipović V, Böhm V. Comparison of chemical profile and antioxidant capacity of seeds and oils from Salvia sclarea and Salvia officinalis. Chem Biodivers 2017; 14: e1700344

[12] Sharma OP, Bhat TK. DPPH antioxidant assay revisited. Food Chem 2009; 113: $1202-1205$

[13] Becker EM, Nissen LR, Skibsted LH. Antioxidant evaluation protocols: food quality or health effects. Eur Food Res Technol 2004; 219: 561-571

[14] Rowshan V, Najafian S. Polyphenolic contents and antioxidant activities of aerial parts of Salvia multicaulis from the Iran flora. Nat Prod Res 2019; $0: 1-3$

[15] Pereira OR, Catarino MD, Afonso AF, Silva AMS, Cardoso SM. Salvia elegans, Salvia greggii and Salvia officinalis decoctions: antioxidant activities and inhibition of carbohydrate and lipid metabolic enzymes. Molecules 2018; 23: E3169

[16] Almada-Taylor G, Díaz-Rubio L, Salazar-Aranda R, Waksman de Torres N, Uranga-Solis C, Delgadillo-Rodríguez J, Ramos MA, Padrón JM, Hernández-Martínez R, Córdova-Guerrero I. Biological activities of extracts from aerial parts of Salvia pachyphylla Epling Ex Munz. Plants 2018; 7: E105

[17] Kamatou GPP, Viljoen AM, Gono-Bwalya AB, van Zyl RL, van Vuuren SF, Lourens ACU, Başer KHC, Demirci B, Lindsey KL, van Staden J, Steenkamp P. The in vitro pharmacological activities and a chemical investigation of three South African Salvia species. J Ethnopharmacol 2005; 102: 382390

[18] Pavić V, Jakovljević M, Molnar M, Jokić S. Extraction of carnosic acid and carnosol from sage (Salvia officinalis L.) leaves by supercritical fluid extraction and their antioxidant and antibacterial activity. Plants 2019; 8: E16

[19] Safari MR, Azizi O, Heidary SS, Kheiripour N, Ravan AP. Antiglycation and antioxidant activity of four Iranian medical plant extracts. J Pharmacopuncture 2018; 21: 82-89

[20] Antolić A, Maleš Ž, Tomičić M, Bojić M. The effect of short-toothed and Dalmatian sage extracts on platelet aggregation. Food Technol Biotechnol 2018; 56: 265-269

[21] Kowalczyk A, Biskup I, Fecka I. Total phenolic content and antioxidative properties of commercial tinctures obtained from some Lamiaceae plants. Nat Prod Commun 2012; 7: 1631-1634

[22] Boukhary R, Raafat K, Ghoneim Al, Aboul-Ela M, El-Lakany A. Anti-inflammatory and antioxidant activities of Salvia fruticosa: An HPLC determination of phenolic contents. Evid Based Complement Alternat Med 2016; 2016: 7178105

[23] Garcia CSC, Menti C, Lambert APF, Barcellos T, Moura S, Calloni C, Branco CS, Salvador M, Roesch-Ely M, Henriques JAP. Pharmacological perspectives from Brazilian Salvia officinalis (Lamiaceae): antioxidant, and antitumor in mammalian cells. An Acad Bras Cienc 2016; 88: 281-292 
[24] Benedec D, Hanganu D, Oniga I, Tiperciuc B, Olah NK, Raita O, Bischin C, Silaghi-Dumitrescu R, Vlase L. Assessment of rosmarinic acid content in six Lamiaceae species extracts and their antioxidant and antimicrobial potential. Pak J Pharm Sci 2015; 28: 2297-2303

[25] Molnar M, Jerković I, Suknović D, Rajs BB, Aladić K, Šubarić D, Jokić S. Screening of six medicinal plant extracts obtained by two conventional methods and supercritical CO- extraction targeted on coumarin content, 2, 2-diphenyl-1-picrylhydrazyl radical scavenging capacity and total phenols content. Molecules 2017; 22: E348

[26] Rababah TM, Ereifej KI, Esoh RB, Al-u'datt MH, Alrababah MA, Yang W. Antioxidant activities, total phenolics and HPLC analyses of the phenolic compounds of extracts from common Mediterranean plants. Nat Prod Res 2011; 25: 596-605

[27] Neagu E, Roman GP, Radu GL. Antioxidant capacity of some Salvia officinalis concentrated extracts. Rev Roum Chim 2011; 56: 777-782

[28] Bandoniene D, Murkovic M, Venskutonis PR. Determination of rosmarinic acid in sage and borage leaves by high-performance liquid chromatography with different detection methods. J Chromatogr Sci 2005; 43: 372-376

[29] Cieśla Ł, Staszek D, Hajnos M, Kowalska T, Waksmundzka-Hajnos M. Development of chromatographic and free radical scavenging activity fingerprints by thin-layer chromatography for selected Salvia species. Phytochem Anal 2011; 22: 59-65

[30] Cieśla Ł, Staszek D, Kowalska T, Waksmundzka-Hajnos M. The use of TLC$\mathrm{DPPH}^{*}$ test with image processing to study direct antioxidant activity of phenolic acid fractions of selected Lamiaceae family species. J AOAC Int 2013; 96: 1228-1232

[31] Miura K, Kikuzaki H, Nakatani N. Antioxidant activity of chemical components from sage (Salvia officinalis L.) and thyme (Thymus vulgaris L.) measured by the oil stability index method. J Agric Food Chem 2002; 50: 1845-1851

[32] Capek P, Machová E, Turjan J. Scavenging and antioxidant activities of immunomodulating polysaccharides isolated from Salvia officinalis L. Int J Biol Macromol 2009; 44: 75-80

[33] Exarchou V, Nenadis N, Tsimidou M, Gerothanassis IP, Troganis A, Boskou D. Antioxidant activities and phenolic composition of extracts from Greek oregano, Greek sage, and summer savory. J Agric Food Chem 2002; 50: 5294-5299

[34] Wang M, Shao Y, Li ], Zhu N, Rangarajan M, LaVoie E], Ho CT. Antioxidative phenolic glycosides from sage (Salvia officinalis). J Nat Prod 1999; 62: 454-456

[35] Ramu G, Dhanabal SP. Antioxidant studies on ethanol extracts from two selected genera of Indian Lamiaceae. Indian J Pharm Sci 2015; 77: 780782

[36] Generalić I, Skroza D, Surjak J, Možina SS, Ljubenkov I, Katalinić A, Simat V, Katalinić V. Seasonal variations of phenolic compounds and biological properties in sage (Salvia officinalis L.). Chem Biodivers 2012; 9: 441457

[37] Lamien-Meda A, Nell M, Lohwasser U, Börner A, Franz C, Novak J. Investigation of antioxidant and rosmarinic acid variation in the sage collection of the genebank in Gatersleben. J Agric Food Chem 2010; 58: 3813-3819

[38] Grzegorczyk-Karolak I, Kiss AK. Determination of the phenolic profile and antioxidant properties of Salvia viridis L. Shoots: a comparison of aqueous and hydroethanolic extracts. Molecules 2018; 23: E1468

[39] Hossain MB, Brunton NP, Martin-Diana AB, Barry-Ryan C. Application of response surface methodology to optimize pressurized liquid extraction of antioxidant compounds from sage (Salvia officinalis L.), basil (Ocimum basilicum L.) and thyme (Thymus vulgaris L.). Food Funct 2010; 1: 269277

[40] Zheng W, Wang SY. Antioxidant activity and phenolic compounds in selected herbs. J Agric Food Chem 2001; 49: 5165-5170
[41] Walch SG, Lachenmeier DW, Kuballa T, Stühlinger W, Monakhova YB. Holistic control of herbal teas and tinctures based on sage (Salvia officinalis L.) for compounds with beneficial and adverse effects using NMR spectroscopy. Anal Chem Insights 2012; 7: 1-12

[42] Celano R, Piccinelli AL, Pagano I, Roscigno G, Campone L, De Falco E, Russo M, Rastrelli L. Oil distillation wastewaters from aromatic herbs as new natural source of antioxidant compounds. Food Res Int 2017; 99: 298-307

[43] Walch SG, Tinzoh LN, Zimmermann BF, Stühlinger W, Lachenmeier DW. Antioxidant capacity and polyphenolic composition as quality indicators for aqueous infusions of Salvia officinalis L. (sage tea). Front Pharmacol 2011; 2: 79

[44] Zupkó I, Hohmann J, Rédei D, Falkay G, Janicsák G, Máthé I. Antioxidant activity of leaves of Salvia species in enzyme-dependent and enzyme-independent systems of lipid peroxidation and their phenolic constituents. Planta Med 2001; 67: 366-368

[45] Hohmann J, Zupkó I, Rédei D, Csányi M, Falkay G, Máthé I, Janicsák G. Protective effects of the aerial parts of Salvia officinalis, Melissa Officinalis and Lavandula angustifolia and their constituents against enzyme-dependent and enzyme-independent lipid peroxidation. Planta Med 1999; 65: 576-578

[46] Malencić D, Gašić O, Popović M, Boža P. Screening for antioxidant properties of Salvia reflexa Hornem. Phytother Res 2000; 14: 546-548

[47] Alaniia M, Shalashvili K, Sagareishvili T, Kavtaradze N, Sutiashvili M. Study of antioxidant activity of phenolic compounds from some species of Georgian flora. Georgian Med News 2013; 222: 69-72

[48] Šulniūtè V, Ragažinskienė O, Venskutonis PR. Comprehensive evaluation of antioxidant potential of 10 Salvia species using high pressure methods for the isolation of lipophilic and hydrophilic plant fractions. Plant Foods Hum Nutr 2016; 71: 64-71

[49] Cocan I, Alexa E, Danciu C, Radulov I, Galuscan A, Obistioiu D, Morvay AA, Sumalan RM, Poiana MA, Pop G, Dehelean CA. Phytochemical screening and biological activity of Lamiaceae family plant extracts. Exp Ther Med 2018; 15: 1863-1870

[50] Martins N, Barros L, Santos-Buelga C, Henriques M, Silva S, Ferreira ICFR. Evaluation of bioactive properties and phenolic compounds in different extracts prepared from Salvia officinalis L. Food Chem 2015; 170: 378385

[51] Matsingou TC, Petrakis N, Kapsokefalou M, Salifoglou A. Antioxidant activity of organic extracts from aqueous infusions of sage. J Agric Food Chem 2003; 51: 6696-6701

[52] Mariutti LRB, Nogueira GC, Bragagnolo N. Lipid and cholesterol oxidation in chicken meat are inhibited by sage but not by garlic. J Food Sci 2011; 76: C909-C915

[53] Cutillas AB, Carrasco A, Martinez-Gutierrez R, Tomas V, Tudela J. Salvia officinalis L. Essential oils from Spain: determination of composition, antioxidant capacity, antienzymatic, and antimicrobial bioactivities. Chem Biodivers 2017; 14: e1700102

[54] Pellegrini M, Ricci A, Serio A, Chaves-López C, Mazzarrino G, D’Amato S, Lo Sterzo C, Paparella A. Characterization of Essential Oils Obtained from Abruzzo Autochthonous Plants: Antioxidant and Antimicrobial Activities Assessment for Food Application. Foods 2018; 7: E19

[55] Khedher MRB, Khedher SB, Chaieb I, Tounsi S, Hammami M. Chemical composition and biological activities of Salvia officinalis essential oil from Tunisia. EXCLI J 2017; 16: 160-173

[56] Ben Farhat M, Jordán M], Chaouech-Hamada R, Landoulsi A, Sotomayor JA. Variations in essential oil, phenolic compounds, and antioxidant activity of tunisian cultivated Salvia officinalis L. J Agric Food Chem 2009; 57: 10349-10356

[57] Dawidowicz AL, Olszowy M. Does antioxidant properties of the main component of essential oil reflect its antioxidant properties? The comparison of antioxidant properties of essential oils and their main components. Nat Prod Res 2014; 28: 1952-1963 
[58] Miguel G, Cruz C, Faleiro ML, Simões MTF, Figueiredo AC, Barroso JG, Pedro LG. Salvia officinalis L. essential oils: effect of hydrodistillation time on the chemical composition, antioxidant and antimicrobial activities. Nat Prod Res 2011; 25: 526-541

[59] Papageorgiou V, Gardeli C, Mallouchos A, Papaioannou M, Komaitis M. Variation of the chemical profile and antioxidant behavior of Rosmarinus officinalis L. and Salvia fruticosa Miller grown in Greece. J Agric Food Chem 2008; 56: 7254-7264

[60] Bozin B, Mimica-Dukic N, Samojlik I, Jovin E. Antimicrobial and antioxidant properties of rosemary and sage (Rosmarinus officinalis L. and Salvia officinalis L., Lamiaceae) essential oils. J Agric Food Chem 2007; 55 : 7879-7885

[61] Hodaj-Çeliku E, Tsiftsoglou O, Shuka L, Abazi S, Hadjipavlou-Litina D, Lazari D. Antioxidant activity and chemical composition of essential oils of some aromatic and medicinal plants from Albania. Nat Prod Commun 2017; 12: 785-790

[62] Ramos AA, Azqueta A, Pereira-Wilson C, Collins AR. Polyphenolic compounds from Salvia species protect cellular DNA from oxidation and stimulate DNA repair in cultured human cells. J Agric Food Chem 2010; 58: 7465-7471

[63] Ramos AA, Pedro D, Collins AR, Pereira-Wilson C. Protection by Salvia extracts against oxidative and alkylation damage to DNA in human HCT15 and CO115 cells. J Toxicol Environ Health A 2012; 75: 765-775

[64] Aherne SA, Kerry JP, O’Brien NM. Effects of plant extracts on antioxidant status and oxidant-induced stress in Caco-2 cells. Br J Nutr 2007; 97 : 321-328

[65] Lima CF, Valentao PCR, Andrade PB, Seabra RM, Fernandes-Ferreira M, Pereira-Wilson C. Water and methanolic extracts of Salvia officinalis protect $\mathrm{HepG} 2$ cells from t-BHP induced oxidative damage. Chem Biol Interact 2007; 167: 107-115

[66] Gong J, Ju A, Zhou D, Li D, Zhou W, Geng W, Li B, Li L, Liu Y, He Y, Song $M$, Wang $Y, Y e Z$, Lin R. Salvianolic acid Y: a new protector of PC12 cells against hydrogen peroxide-induced injury from Salvia officinalis. Molecules 2015; 20: 683-692

[67] Kozics K, Klusová V, Srančíková A, Mučaji P, Slameňová D, Hunáková L, Kusznierewicz B, Horváthová E. Effects of Salvia officinalis and Thymus vulgaris on oxidant-induced DNA damage and antioxidant status in HepG2 cells. Food Chem 2013; 141: 2198-2206

[68] Porres-Martínez M, González-Burgos E, Carretero ME, Gómez-Serranillos MP. Protective properties of Salvia lavandulifolia Vahl. essential oil against oxidative stress-induced neuronal injury. Food Chem Toxicol 2015; 80: 154-162

[69] Porres-Martínez M, González-Burgos E, Carretero ME, Gómez-Serranillos MP. Major selected monoterpenes $\alpha$-pinene and 1, 8-cineole found in Salvia lavandulifolia (Spanish sage) essential oil as regulators of cellular redox balance. Pharm Biol 2015; 53: 921-929

[70] Kim JY, Kim HS, Kang HS, Choi JS, Yokozawa T, Chung HY. Antioxidant potential of dimethyl lithospermate isolated from Salvia miltiorrhiza (red sage) against peroxynitrite. J Med Food 2008; 11: 21-28

[71] Brahmi N, Scognamiglio M, Pacifico S, Mekhoukhe A, Madani K, Fiorentino A, Monaco P. ${ }^{1} \mathrm{H}$ NMR based metabolic profiling of eleven Algerian aromatic plants and evaluation of their antioxidant and cytotoxic properties. Food Res Int 2015; 76: 334-341
[72] Vaško L, Vašková ], Fejerčáková A, Mojžišová G, Poráčová ]. Comparison of some antioxidant properties of plant extracts from Origanum vulgare, Salvia officinalis, Eleutherococcus senticosus and Stevia rebaudiana. In Vitro Cell Dev Biol Anim 2014; 50: 614-622

[73] Chohan M, Naughton DP, Jones L, Opara El. An investigation of the relationship between the anti-inflammatory activity, polyphenolic content, and antioxidant activities of cooked and in vitro digested culinary herbs. Oxid Med Cell Longev 2012; 2012: 627843

[74] Güzel S, Özay Y, Kumaş M, Uzun C, Özkorkmaz EG, Yıldırım Z, Ülger M, Güler G, Çelik A, Çamlıca Y, Kahraman A. Wound healing properties, antimicrobial and antioxidant activities of Salvia kronenburgii Rech. f. and Salvia euphratica Montbret, Aucher \& Rech. f. var. euphratica on excision and incision wound models in diabetic rats. Biomed Pharmacother 2019; 111: 1260-1276

[75] Zhou R, Long H, Zhang B, Lao Z, Zheng Q, Wang T, Zhang Y, Wu Q, Lai X, Li G, Lin L. Salvianolic acid B, an antioxidant derived from Salvia militarize, protects mice against $y$-radiation-induced damage through Nrf2/Bach1. Mol Med Rep 2019; 19: 1309-1317

[76] Gião MS, Pestana D, Faria A, Guimarães JT, Pintado ME, Calhau C, Azevedo I, Malcata FX. Effects of extracts of selected medicinal plants upon hepatic oxidative stress. J Med Food 2010; 13: 131-136

[77] El-Hosseiny LS, Alqurashy NN, Sheweita SA. Oxidative stress alleviation by sage essential oil in co-amoxiclav induced hepatotoxicity in rats. Int J Biomed Sci 2016; 12: 71-78

[78] Hasanein P, Felehgari Z, Emamjomeh A. Preventive effects of Salvia officinalis $\mathrm{L}$. against learning and memory deficit induced by diabetes in rats: Possible hypoglycaemic and antioxidant mechanisms. Neurosci Lett 2016; 622: 72-77

[79] Placha I, Ryzner M, Cobanova K, Faixova Z, Faix S. Effects of dietary supplementation with sage (Salvia officinalis L.) essential oil on antioxidant status and duodenal wall integrity of laying strain growers. Pol J Vet Sci 2015; 18: 741-749

[80] Horváthová E, Srančíková A, Regendová-Sedláčková E, Melušová M Meluš V, Netriová J, Krajčovičová Z, Slameňová D, Pastorek M, Kozics K. Enriching the drinking water of rats with extracts of Salvia officinalis and Thymus vulgaris increases their resistance to oxidative stress. Mutagenesis 2016; 31: 51-59

[81] Fehresti Sani M, Montasser Kouhsari S, Moradabadi L. Effects of three medicinal plants extracts in experimental diabetes: antioxidant enzymes activities and plasma lipids profiles in comparison with metformin. Iran J Pharm Res 2012; 11: 897-903

[82] Kolac UK, Ustuner MC, Tekin N, Ustuner D, Colak E, Entok E. The anti-inflammatory and antioxidant effects of Salvia officinalis on lipopolysaccharide-induced inflammation in rats. J Med Food 2017; 20: 1193-1200

[83] Sönmez AY, Bilen S, Alak G, Hisar O, Yanık T, Biswas G. Growth performance and antioxidant enzyme activities in rainbow trout (Oncorhynchus mykiss) juveniles fed diets supplemented with sage, mint and thyme oils. Fish Physiol Biochem 2015; 41: 165-175

[84] Lima CF, Andrade PB, Seabra RM, Fernandes-Ferreira M, Pereira-Wilson C. The drinking of a Salvia officinalis infusion improves liver antioxidant status in mice and rats. J Ethnopharmacol 2005; 97: 383-389

[85] Sá CM, Ramos AA, Azevedo MF, Lima CF, Fernandes-Ferreira M, PereiraWilson C. Sage tea drinking improves lipid profile and antioxidant defences in humans. Int J Mol Sci 2009; 10: 3937-3950 